\title{
LA DECISIÓN MARCO 2005/212: ANTECEDENTE Y ORIGEN DE LAS ÚLTIMAS REFORMAS DEL COMISO COMO CONSECUENCIA ACCESORIA DEL DELITO*
}

\author{
The framework decision 2005/212: background \\ and origin of the last reform of the confiscation \\ as a consequence of crime accessory
}

Itziar Casanueva Sanz

Itziar.casanueva@deusto.es

Soledad Gil Nobajas

sgil@deusto.es

Emilio José Armaza Armaza

Emilio.armaza@deusto.es

Universidad de Deusto (España)

http://dx.doi.org/10.18543/ed-66(2)-2018pp397-434

Recibido: 03.09.2018

Aceptado: 21.01.2018

\section{Resumen}

Este artículo analizará un aspecto que está cobrando cada vez una importancia mayor como mecanismo adecuado para evitar que el grupo organizado obtenga

* Cómo citar / Citation 'Chicago-Deusto' (Autor-fecha / Author-date / Lista de referencias / Reference list entries): Casanueva, Itziar; Gil Soledad; Armaza Emilio José. 2018. «La decisión marco 2005/212: antecedente y origen de las últimas reformas del comiso como consecuencia accesoria del delito». Estudios de Deusto 66, n. ${ }^{\circ} 2$ : 397-434. http://dx.doi.org/10.18543/ed-66(2)-2018pp397-434. 
ningún tipo de beneficio por la comisión de infracciones penales, así como para permitir la recuperación y gestión económica de los activos procedentes del delito de un modo más eficaz: la figura del comiso. Para ello nos centraremos, básicamente, en dos documentos de capital importancia: La DM 2005/212, de 24 de febrero de 2005, relativa al decomiso de los productos, instrumentos y bienes relacionados con el delito y la Directiva 2014/42/UE del Parlamento Europeo y del Consejo de 3 de abril de 2014 sobre el embargo y el decomiso de los instrumentos y del producto del delito en la Unión Europea.

\section{Palabras clave}

Comiso; Europeización Derecho penal; Derecho penal económico.

\section{Abstract}

This article will analyze an aspect that is becoming increasingly important as an adequate mechanism to prevent the organized group from obtaining any type of benefit for the commission of criminal offenses, as well as to allow the recovery and economic management of assets derived from the crime of a more efficient way: the figure of confiscation. For this we will focus, basically, on two documents of capital importance: The DM 2005/212, of February 24, 2005, regarding the confiscation of the products, instruments and goods related to the crime and Directive 2014/42 / EU of the European Parliament and the Council of 3 April 2014 on the seizure and confiscation of instruments and proceeds of crime in the European Union.

\section{Keywords}

Confiscation, Europeanization Criminal law, Economic criminal law. 


\begin{abstract}
SUMARIO: I. INTRODUCCIÓN. II. LA REGULACIÓN COMISO EN EL CÓDIGO PENAL ESPAÑOL CON ANTERIORIDAD A LAS REFORMAS OPERADAS EN VIRTUD DE LOS COMPROMISOS INTERNACIONALES ADQUIRIDOS. 2.1. Introducción. 2.2. Regulación general: arts. 127 y $128 \mathrm{CP}$ del Texto del CP anterior a la reforma penal de 2010. 2.3. Regulación especial del comiso. 2.3.1. Blanqueo de bienes. 2.3.2. Tráfico de drogas. 2.3.3. Seguridad vial, cohecho y tráfico de influencias. III. DECISIÓN MARCO 2005/212 DEL CONSEJO, DE 24 DE FEBRERO DE 2005 RELATIVA AL DECOMISO DE LOS PRODUCTOS, INSTRUMENTOS Y BIENES RELACIONADOS CON EL DELITO. 3.1. Introducción. 3.2. Decomiso de instrumentos y productos. 3.3. Potestad de decomiso ampliada. 3.3.1. Características de la infracción. 3.3.2. Supuestos de aplicación del comiso ampliado. 3.3.3. Cuestiones que suscita el decomiso ampliado. 3.3.4. Otras previsiones sobre el comiso ampliado. IV. EL IMPACTO DE LA DM 2005/212 EN LA REFORMA PENAL DE 2010. 4.1. Introducción. 4.2. Regulación general (arts. 127 y 128 CP). 4.2.1. Comiso y personas jurídicas. 4.2.2. El comiso en los delitos imprudentes. 4.2.3. El comiso ampliado. 4.3. Regulación especial. 4.3.1. Blanqueo de bienes. 4.3.2. Tráfico de drogas. 4.3.3. Seguridad vial.
\end{abstract}

\title{
I. INTRODUCCIÓN
}

Es una opinión asumida unánimemente que la Unión Europea no posee competencia penal. Sólo los Estados miembros, como Estados soberanos, pueden definir la materia criminal. Cierto es que esta idea resulta cada vez más resbaladiza en un mundo en el que la globalización y el desarrollo tecnológico ha alcanzado todos los ámbitos y en el que también el fenómeno de la delincuencia se ha empapado de esta tendencia. El prototipo de criminalidad de la sociedad post-moderna pasa por la actuación de grupos organizados, con una distribución de roles y funciones, que llevan a cabo sus actuaciones ilícitas en un marco transnacional, obteniendo beneficios que reinvierten en el ciclo delictivo o en sobornos a agentes y autoridades o, incluso, son utilizados para generar negocios lícitos; pero en todo caso se trata de actuaciones que ponen en jaque a la actuación policial y judicial de cada Estado miembro. La preocupante magnitud de los efectos de lo que se conoce como «criminalidad organizada» no ha pasado desapercibida por la Unión Europea ni por otras organizaciones regionales e internacionales que, conscientes de su amenaza, han centrado una de sus actuaciones prioritarias de los últimos años a la elaboración y aplicación de medidas destinadas a prevenir y controlar la delincuencia organizada que opera en su ámbito geográfico ${ }^{1}$.

${ }^{1}$ Por ejemplo, hay que mencionar los Planes de Acción para luchar contra la delincuencia organizada aprobados por el Consejo Europeo de Ámsterdam de junio de 1997 
Dentro de la Unión Europea, tales estrategias se integran en el llamado Tercer Pilar de cooperación intergubernamental, recogido en el Título VI TUE, para la creación de un «espacio de libertad, seguridad y justicia» y en el cual el Derecho Penal ocupa un papel fundamental ${ }^{2}$. Partiendo de este objetivo, son numerosos los Convenios y Decisiones Marco (en adelante DM) que tratan de incidir sobre el problema de la criminalidad organizada. Aunque esto no significa que las instituciones comunitarias hayan comenzado a ostentar competencia penal, es innegable la repercusión que estos instrumentos suponen para los ordenamientos jurídico-penales estatales, puesto que en el caso de las DM imponen, indirectamente, la obligación a los Estados miembros de legislar penalmente conforme a lo previsto en ellas.

No es nuestra intención hacer un recorrido sobre todas las iniciativas comunitarias impulsadas en la búsqueda de una respuesta eficaz a la delincuencia organizada. Solamente nos vamos a centrar en un aspecto muy concreto y que, considerado en un segundo plano en el Derecho Penal sustantivo, está cobrando cada vez una importancia mayor como mecanismo adecuado para evitar que el grupo organizado obtenga ningún tipo de beneficio por la comisión de infracciones penales, así como para permitir la recuperación y gestión económica de los activos procedentes del delito de un modo más eficaz: la figura del comiso. Para ello nos centraremos, básicamente, en dos documentos de capital importancia: La DM 2005/212, de 24 de febrero de 2005 , relativa al decomiso de los productos, instrumentos y bienes relacionados con el delito ${ }^{3}$ y la Directiva 2014/42/UE del Parlamento Europeo y del

(BUE 6-1997), el Consejo Europeo de Viena de diciembre de 1998 (BUE 12-1998), y el Consejo Europeo de Tampere de octubre de 1999 (BUE 10-1999), la Decisión 2002/630/ JAI del Consejo, de 22 de julio de 2002, por la que se establece un programa marco sobre cooperación policial y judicial en materia penal-AGIS (DO L 203 de 1.8.2002), el Plan de Acción del Consejo y de la Comisión por el que se aplica el Programa de La Haya sobre el refuerzo de la libertad, la seguridad y la justicia en la Unión Europea (DO C 198 de 12.8.2005), la Decisión 2007/124/CE del Consejo, de 12 de febrero de 2007, por la que se establece para el período 2007-2013 el programa específico Prevención, preparación y gestión de las consecuencias del terrorismo y de otros riesgos en materia de seguridad, integrado en el programa general Seguridad y defensa de las libertades (DO L 58 de 24.2.2007), la Comunicación de la Comisión al Consejo y al Parlamento Europeo por la que se establece un programa marco Seguridad y defensa de las libertades para el período 2007-2013 (DO L 58 de 24.2.2007), así como el más reciente Programa de Estocolmo Una Europa abierta y segura que sirva y proteja al ciudadano (DO C 115 de 4.5.2010) que define los objetivos del espacio de libertad, seguridad y justicia para el periodo 20102014.

${ }^{2}$ En concreto, el art. 29 TUE habla de la «aproximación, cuando proceda, en materia penal», si bien el art. 31 e) TUE limita esta aproximación, precisamente, a los ámbitos de la delincuencia organizada, terrorismo y tráfico ilícito de drogas.

${ }^{3}$ DO L 68 de 15.3.2005 
Consejo de 3 de abril de 2014 sobre el embargo y el decomiso de los instrumentos y del producto del delito en la Unión Europea. En el presente artículo, analizaremos de forma específica el contenido de la DM 2005/212 con el fin de identificar las novedades y problemas técnico-jurídicos que su implementación (aunque tardía) supuso para nuestra legislación penal. No nos ocuparemos de las novedades que han sido introducidas en la figura del comiso en virtud de la reforma penal de 2015 (inspirada, en relación con este punto, en la Directiva 2014/42/UE) ${ }^{4}$.

\section{LA REGULACIÓN COMISO EN EL CÓDIGO PENAL ESPAÑOL CON ANTERIORIDAD A LAS REFORMAS OPERADAS EN VIRTUD DE LOS COMPROMISOS INTERNACIONALES ADQUIRIDOS}

\section{Introducción}

Desde la publicación del texto original del CP vigente, la figura objeto de estudio se ha regulado, con carácter genérico, en los arts. 127 y $128 \mathrm{CP}$, aglutinando el comiso de efectos, bienes, medios e instrumentos y el comiso de las ganancias provenientes del delito ${ }^{5}$. Ambas modalidades de comiso presentan

${ }^{4}$ Sobre ello, véase con detalle y entre otros: De la Mata Barranco, N.J.: «Las distintas modalidades de decomiso después de la Ley Orgánica 1/2015, de 30 de marzo», en La Ley, 764/2017, pp. 1-13; Gorjón Barranco, M.C.: «El comiso ampliado como paradigma del moderno Derecho penal», en Revista Penal, No 38, Julio 2016, pp. 127-144; Gómez Tomillo, M.: «El comiso de los instrumentos del delito propiedad de terceros no responsables criminalmente del delito», en Estudios jurídico penales y criminológicos. En Homenaje al Prof. Dr. Dr. H. C. Mult. Lorenzo morillas Cueva, Dykinson, Madrid, 2018, pp. 313-326; Díaz López, J.A.: «El partícipe a título lucrativo tras las reformas del decomiso», en La Ley, 7736/2015, pp. 1-25; Dolz Lago, M. J.: «Los decomisos: Aproximación a sus aspectos sustantivos y procesales tras la reforma del 2015», en La Ley, 1250/2017, pp. 1-28; Roig Torres, M.: «El comiso como estrategia frente a la corrupción en Alemania: Interpretación jurisprudencial», en Estudios Penales y Criminológicos, vol. XXXVIII (extr.), 2018, pp. 547-600; ROIG TORRES, M.: «La regulación del comiso. Modelo alemán y la reciente reforma española», en Estudios Penales y Criminológicos, vol. XXXVI, 2016, pp. 199-268.

5 De ahora en adelante, hablaremos de comiso de efectos e instrumentos y de comiso de ganancias. Con ello nos unimos al sentir de una parte de la doctrina que entiende que los términos «medios»y «bienes», incorporados con la reforma del CP por LO 15/2003, de 25 de noviembre, no aportan nada nuevo a los conceptos «instrumentos» y «efectos», pues todo instrumento es medio y a la vez bien. En tal sentido, Gracia Martín, L.: «Las consecuencias accesorias», en Gracia Martín, L. (coord.): Tratado de las consecuencias jurídicas del delito, Tirant lo Blanch, Valencia, 2006, P. 567. Igualmente, Aguado Correa, T.: «La regulación del comiso en el Proyecto de modificación del Código Penal», en RECPC 05-04 (2003), http://criminet.ugr.es/recpc, p. 4, considerando que, incluso, basta- 
ciertas particularidades específicas, aunque a los efectos de este trabajo se pretende contrastar la regulación española y comunitaria, sin entrar a un estudio pormenorizado de todas las cuestiones problemáticas que origina el instituto del comiso en nuestro sistema penal. Al margen de esta normativa general, existen también un número puntual de reglas especiales para los delitos de blanqueo de bienes, tráfico de drogas, seguridad vial y cohecho.

A lo largo de estos (ya) más de 28 años de vigencia del CP, el texto original ${ }^{6}$ que regulaba la figura del decomiso ha sufrido únicamente tres modificaciones. La primera efectuada en el año 2003 (y que entró en vigor a partir del octubre de 2004) introdujo en nuestro sistema penal la posibilidad de efectuar el decomiso por el valor equivalente, así como la posibilidad de acordar el comiso aun cuando no se imponga pena a alguna persona por estar exenta de responsabilidad criminal o por haberse ésta extinguido 7 . En los epígrafes

ba con el término «instrumento» como todo bien o medio utilizado para la ejecución o preparación del delito, pues así se seguiría la misma nomenclatura dispuesta en las normas internacionales sobre la materia; Puente Aba, L.A.: «La nueva regulación del comiso en el Proyecto de Ley Orgánica, de 5 de mayo de 2003, por el que se modifica el Código Penal», AP, núm. 39, 2003, p. 991.

${ }^{6}$ El texto original de los artículos 127 y 128 del CP de 1995 era el que sigue: «Artículo 127. Toda pena que se imponga por un delito o falta dolosos llevará consigo la pérdida de los efectos que de ellos provengan y de los instrumentos con que se haya ejecutado, así como las ganancias provenientes del delito, cualesquiera que sean las transformaciones que hubieren podido experimentar. Los unos y las otras serán decomisados, a no ser que pertenezcan a un tercero de buena fe no responsable del delito que los haya adquirido legalmente. Los que se decomisan se venderán, si son de lícito comercio, aplicándose su producto a cubrir las responsabilidades civiles del penado y, si no lo son, se les dará el destino que se disponga reglamentariamente y, en su defecto, se inutilizarán.

${ }^{A}$ rtículo 128. Cuando los referidos efectos e instrumentos sean de lícito comercio y su valor no guarde proporción con la naturaleza o gravedad de la infracción penal, o se hayan satisfecho completamente las responsabilidades civiles, podrá el Juez o Tribunal no decretar el decomiso, o decretarlo parcialmente».

7 El texto del artículo 127 del CP, conforme a dicha modificación, disponía lo siguiente: «1. Toda pena que se imponga por un delito o falta dolosos llevará consigo la pérdida de los efectos que de ellos provengan y de los bienes, medios o instrumentos con que se haya preparado o ejecutado, así como las ganancias provenientes del delito o falta, cualesquiera que sean las transformaciones que hubieren podido experimentar. Los unos y las otras serán decomisados, a no ser que pertenezcan a un tercero de buena fe no responsable del delito que los haya adquirido legalmente. 2. Si por cualquier circunstancia no fuera posible el comiso de los bienes señalados en el apartado anterior, se acordará el comiso por un valor equivalente de otros bienes que pertenezcan a los criminalmente responsables del hecho. 3. El juez o tribunal podrá acordar el comiso previsto en los apartados anteriores de este artículo aun cuando no se imponga pena a alguna persona por estar exenta de responsabilidad criminal o por haberse ésta extinguido, en este último caso, siempre que quede demostrada la situación patrimonial ilícita. 4. Los que se deco- 
siguientes procederemos a analizar la forma en la cual estaba regulada esta figura hasta antes de la entrada en vigor de las dos últimas modificaciones del CP (ambas, como se ha indicado, fueron introducidas de forma sucesiva y en virtud de sendos compromisos internacionales).

\section{Regulación general: arts. 127 y $128 \mathrm{CP}$ del Texto del CP anterior a la reforma penal de 2010}

La regulación genérica del comiso aparece recogida en el Título VI del Libro I del CP, «De las consecuencias accesorias». De entrada, esta denominación viene dividiendo a la doctrina a la hora de esclarecer su naturaleza jurídica, si bien, mayoritariamente, se asume que se trata de una consecuencia jurídica de naturaleza penal, distinta de la pena y de la medida de seguridad y fundamentada en la peligrosidad objetiva de la cosa ${ }^{8}$. Sin embargo, la mayoría de la doctrina otorga al comiso de ganancias una naturaleza exclusivamente civil o, al menos, una doble naturaleza, civil y penal, puesto que su finalidad es impedir todo enriquecimiento o situación patrimonial ilícita que pudiera obtener un sujeto por la comisión de un delito?.

misan se venderán, si son de lícito comercio, aplicándose su producto a cubrir las responsabilidades civiles del penado si la ley no previera otra cosa, y, si no lo son, se les dará el destino que se disponga reglamentariamente y, en su defecto, se inutilizarán».

${ }^{8}$ De esta opinión, sólo respecto del comiso, Aguado Correa, T.: El comiso, Edersa, Madrid, 2000, pp. 36 y 41; Choclán Montalvo, J.A.: El patrimonio criminal. Comiso y pérdida de la ganancia, Dykinson, Madrid, 2001, pp. 29 y 40; Manzanares Samaniego, J.L.: «Notas sobre el comiso y la propiedad de terceros», en AP, 1997, p. 524; Mapelli Caffarena, B.: «Las consecuencias accesorias en el nuevo Código Penal», en Rev. Penal, 1998, p. 51; Octavio de Toledo y Ubierto, E.: «El comiso», La Ley, núm. 5495, 2002, pp. 1567-1568.; Ramón Ribas, E.: «La transformación jurídica del comiso: de pena a consecuencia accesorias», en EPC, 2002-2003, pp. 531-532, 538 y 547. La considera una auténtica pena, Bacigalupo Sagesse, S.: Ganancias ilícitas y Derecho Penal, Centro de Estudios Ramón Areces, Madrid, 2002, p. 87. Por el contrario, Gracia Martín le niega todo carácter sancionatorio, catalogándola como una medida administrativa coercitiva o civil. En «Las consecuencias..., op. cit., pp. 552 y 562.

9 Así, con matices, Aguado Correa, T.: El comiso..., op. cit., pp. 79 y 81; Gracia Martín, L.: «Las consecuencias..., op. cit., pp. 552, 562, 569 y 573, este último en relación al comiso del valor equivalente; Manzanares Samaniego, J.L.: «Notas..., op. cit., p. 527, aunque no del todo claro; Mapelli Caffarena, B.: «Las consecuencias..., op. cit., p. 50; Ramón Ribas, E.: «La transformación..., op. cit., p. 539; Roca Agapito, L.: El sistema de sanciones en el Derecho Penal español, Bosch, Barcelona, 2007, p. 578 sobre el comiso de ganancias y p. 584 respecto del comiso del valor equivalente.

Es importante diferenciar la naturaleza jurídica de ambas modalidades de comiso por la repercusión que este aspecto puede tener en cuanto a una posible flexibilización de la carga de la prueba que plantea el comiso ampliado de cara a una futura regulación penal. 
Como veremos más adelante, tanto el comiso de los efectos e instrumentos como el comiso de ganancias, regulados en el art. 127, se identifican legislativamente con la previsión del art. 2 DM 2005/212 cuando habla del decomiso de los instrumentos y productos de infracciones penales. Fuera de estas líneas queda toda consideración al comiso ampliado del art. 3 DM. Pero incluso dentro de estos márgenes, el decomiso no es posible para toda infracción, sino únicamente para los delitos y faltas dolosos. Esto también se aleja, en parte, del contenido del art. 2 de nuestra DM, dado que la regulación española resulta, en algunos aspectos, más restrictiva, mientras que en otros puntos es más amplia.

Es más limitativa porque el art. $127 \mathrm{CP}$ dejaba fuera (hasta la reforma del año 2010), explícitamente, a los delitos imprudentes ${ }^{10}$. Y también podría pensarse que es más amplia, debido a que acogía los delitos y a las -ya derogadas- faltas, mientras que la DM limita el comiso de instrumentos y productos a las infracciones que lleven asignada una pena privativa de libertad superior a un año. No obstante, este límite parece que debe interpretarse como la pena individualizada en sentencia, de manera que la DM permitiría excluir algunos delitos menos graves y las faltas, según la antigua clasificación de las infracciones penales en el Derecho Penal español. En todo caso, las diferencias no hacen incompatibles ambas regulaciones, pues la DM 2005/212 establece la obligatoriedad del comiso para las infracciones con una pena privativa de libertad de un año, pero no impide que, según el derecho interno de cada Estado, pueda extenderse también a las infracciones (en nuestro caso, delitos menos graves y faltas) con una penalidad inferior.

El comiso de los efectos e instrumentos y el comiso de ganancias es de preceptiva aplicación, ex art. 127.1, por la imposición de una pena por delito o falta doloso. Sin embargo, existían dos condiciones que pueden evitarlo: si los efectos, instrumentos o ganancias pertenecen a un tercero de buena fe no responsable del delito que los haya adquirido legalmente, no podrán ser decomisados ${ }^{11}$ (art. 127.1 in fine). Pero además, aunque no se diera este supuesto, el órgano judicial podía decidir no decretar el comiso, o acordarlo parcialmente, cuando los efectos e instrumentos sean de lícito comercio y su

${ }^{10}$ La exclusión de los delitos imprudentes del ámbito de aplicación del comiso surge del CP de 1995 y se mantiene hasta hoy. El viejo CP admitía el comiso (como pena accesoria) tanto para hechos dolosos como imprudentes lo cual, precisamente, era y es criticado por la doctrina. Vid., Landrove Díaz, G.: Las consecuencias jurídicas del delito, 6 a ed., Tecnos, Madrid, 205, pp. 129-130; Roca Agapito, L.: El sistema..., op. cit., p. 585. A favor del sometimiento de los delitos imprudentes a la regulación del comiso, Aguado Correa, T.: El comiso..., op. cit., p. 99, La misma: «La regulación..., op. cit., p. 16.

${ }^{11}$ Críticamente sobre este aspecto, Manzanares Samaniego, J.L.: «notas..., op. cit., pp. 532-533. 
valor no guarde proporción con la naturaleza o gravedad de la infracción penal, o se hayan satisfecho completamente las responsabilidades civiles (art. $128 \mathrm{CP}$ ). Esta última condición, no obstante, sólo afecta al comiso de efectos e instrumentos, no así al de ganancias.

Por otro lado, el comiso podía ser viable aun cuando no se imponga pena alguna. Así lo declaraba el apartado 3 del art. $127 \mathrm{CP}$, en virtud del cual el órgano judicial está facultado potestativamente para acordar el comiso aunque no se haya impuesto pena, sea por exención o por extinción de la responsabilidad penal, siempre que quede demostrada la situación patrimonial ilícita $^{12}$.

La DM guarda silencio sobre cualquier excepción a la obligatoriedad del comiso (al margen del requisito de la pena de prisión superior al año) o sobre la posibilidad de decretarlo aunque no exista responsabilidad penal. No creemos que eso sea obstáculo para afirmar su compatibilidad con la regulación española, pues en la medida en que se respete la propuesta planteada en sus líneas fundamentales, los Estados miembros tienen margen para acoplar y ampliar las previsiones de conformidad a su derecho interno.

Siguiendo con la vieja regulación española, el comiso es factible a pesar de las transformaciones que hubieran podido experimentar los efectos, instrumentos y ganancias. Es decir, en caso de que no pudiera privarse de estos bienes (por haber desaparecido, haber sido destruidos, o por pertenecer a un tercero de buena fe no responsable del delito que los haya adquirido legalmente), el juez o tribunal decretará el llamado «comiso por valor equivalente», privando al condenado de otros bienes de origen lícito cuyo valor se corresponda con los anteriores ${ }^{13}$. Idéntica observación se realiza en el último inciso del art. 2.1 DM, aunque en este caso se habla de «bienes cuyo valor

${ }_{12}$ Como se ha indicado, este inciso fue incorporado al art. 127 CP por LO 15/2003, de 25 de noviembre. A raíz de su inclusión y teniendo en cuenta la caracterización del comiso como consecuencia accesoria, parece que quedaría zanjada la cuestión de si la accesoriedad se refiere a la pena, pues ya no se exigiría condena en todo caso para poder acordar estas medidas. Favorable a su inclusión, con carácter genérico, Gracia Martín, L.: «Las consecuencias..., op. cit., p. 563; en relación al art. 374 CP, Manzanares Samaniego, J.L.: «Notas..., op. cit., p. 535. Reconoce que tras la LO 15/2003 el comiso es accesorio del delito, Roca Agapito, L.: El sistema..., op. cir., p. 578. Una visión crítica del art. 127.3, con los problemas que plantea la ofrecen Aguado Correa, T.: «La regulación..., op. cit., pp. 7-8, Puente Aba, L.M.: «La nueva regulación..., op. cit., pp. 986 y ss.

13 Esta previsión también se incluyó por la reforma del CP mediante LO 15/2003, dando así cumplimiento, tardío, al art. 2.1 Convenio de 1990 y al art. 3 DM 2001/500. Este último texto debería haberse incorporado al ordenamiento jurídico español, como fecha tope, el 31 de diciembre de 2002. Con una visión favorable de esta consagración, aunque resaltando sus aspectos criticables, Aguado Correa, R.: «La regulación..., op. cit., pp. 5-6. 
corresponda a tales productos». Atendiendo a la definición de «productos» del art. $1 \mathrm{DM}$, en principio habría que entender que se limita a los «beneficios económicos derivados de la infracción, lo que podrá consistir en cualquier clase de bienes». Ahondando más en esta cuestión terminológica, la DM incluye en el concepto de bienes los materiales, inmateriales, muebles o inmuebles, "así como los actos jurídicos o documentos que acrediten la titularidad otros derechos sobre tales bienes». Parece desprenderse, en consecuencia, que el comiso del valor equivalente se circunscribe exclusivamente a todo aquello que se haya obtenido con el delito, no a lo utilizado en su preparación o ejecución. Es decir, desde el punto de vista de la regulación española abarcaría los efectos y ganancias del delito, pero no los instrumentos ${ }^{14}$. A pesar de estas consideraciones, de nuevo no se plantea ningún problema de compatibilidad, puesto que el art. 127.3 CP supone un plus en este punto respecto de la DM, no una carencia sustancial.

Por último, aunque sobre esta cuestión no se pronuncie al DM, recordar que en nuestro Derecho Penal el destino de los bienes confiscados es cubrir las responsabilidades penales, mediante su venta si son de lícito comercio, a menos que la ley disponga otra cosa. Si no fueran de lícito comercio, habrá que estar a lo que se establezca reglamentariamente y, en su defecto, se inutilizarán (art.127.4 CP) $)^{15}$.

\section{Regulación especial del comiso}

Las disposiciones comentadas de los arts. 127 y 128 CP no completaban toda la regulación penal española en materia de comiso. Determinados delitos de la Parte Especial del CP ya incorporaban una serie de reglas específicas sobre esta cuestión, algunas sustanciales, otras procedimentales y, en algunos casos, suponen simplemente una mera reiteración de la regulación general. Cuatro son los ámbitos delictivos que se ven afectados: blanqueo de bienes, tráfico de drogas, seguridad vial y cohecho y tráfico de influencias. De especial interés resultan los dos primeros, pues estamos ante dos infracciones penales que, de darse sus presupuestos, encajarían en las disposiciones del art. 3 DM 2005/212. No obstante, nuevamente conviene adelantar dos observaciones: tampoco en esta regulación especial encontraremos concordancia con

${ }^{14}$ Salvo que se interpretase teleológicamente el último inciso del art. 2.1 DM en el sentido de que al hablar de «productos» debe hacerse extensible a los instrumentos. Desde luego, tal interpretación sería más acorde con la finalidad pretendida por la DM de luchar contra la criminalidad organizada.

15 Respecto de esta última cuestión, hay que tener presente lo que específicamente se prevé para el delito de blanqueo de bienes y tráfico de drogas del art. $374 \mathrm{CP}$ en cuanto a tramitación y destino de los objetos confiscados. 
las propuestas de la Unión Europea respecto del comiso ampliado. Y, en segundo lugar, la aplicación de estas normas específicas no desvirtúa lo dispuesto con carácter genérico en los arts. 127 y $128 \mathrm{CP}$, que rigen en todo aquello no cubierto por las reglas especiales.

\subsection{Blanqueo de bienes}

Parte de las propuestas de la Unión Europea en materia de blanqueo de bienes y capitales sobre confiscación ya se han visto incorporadas parcialmente en nuestro CP. En concreto, el comiso de valor equivalente previsto en el art. 3 DM 2001/500, disposición que fue incorporada, con carácter genérico, a la regulación penal española mediante LO 15/2003, de 25 de noviembre, modificadora del CP, con la introducción de un nuevo apartado 2 al art. 127, ya comentado. En cuanto a la mención expresa del comiso en el blanqueo de bienes, aparece reflejada en los arts. 301.1, párrafo segundo y art. 302.2 CP.

\subsubsection{Art. 301.1., segundo párrafo CP:}

Este precepto contempla una agravación del tipo básico del blanqueo de capitales cuando la adquisición, conversión o transmisión de bienes o el encubrimiento real o personal a los que se refiere el primer apartado del art. $301 \mathrm{CP}$ recaigan sobre bienes que proceden de alguno de los delitos de tráfico de drogas de los artículos 368 a 372 CP. En estos casos, además de imponerse la pena en la mitad superior a la persona condenada, el precepto remite expresamente al contenido del art. $374 \mathrm{CP}$, relativo a las reglas específicas del comiso en materia de tráfico de drogas.

En realidad, el art. $374 \mathrm{CP}$ refleja más una regulación procesal que sustantiva. A nuestros efectos, merecen ser destacados dos aspectos (que también operan, por extensión, para los delitos de tráfico de drogas, como veremos). El objeto del delito en estos tipos penales (drogas tóxicas, estupefacientes, sustancias psicotrópicas, equipos, materiales, etc) también serán objeto de comiso (art. 374.1 CP) ${ }^{16}$. Y como segunda consideración, el apartado $5^{\circ}$ del

${ }^{16}$ Con ello se salva la objeción teórica, puesta de manifiesto por la doctrina, de que el objeto del delito no es ni instrumento, ni efecto, ni producto de éste y de que se necesita una regla específica que excepcione la regla general, Aguado Correa, T.: «La regulación..., op. cit., p. 16; Gracia Martín, L.: «Las consecuencias..., op. cit., p. 566; Manzanares Samaniego, J.L.: «notas..., op. cit., p. 534.

El resto del contenido del art. $374.1 \mathrm{CP}$, esto es, la sujeción de los bienes, medios, instrumentos y ganancias a lo dispuesto en el artículo 127 del Código no es más que un 
art. $374.1 \mathrm{CP}^{17}$ nos recuerda que se aplicará el comiso del valor equivalente cuando los bienes, medios, instrumentos y ganancias del delito hayan desaparecido del patrimonio del penalmente responsable, lo cual no aporta nada nuevo al art. $127 \mathrm{CP}$ como regulación general.

\subsubsection{Art. $302.2 \mathrm{CP}$}

Cuando el blanqueo de bienes se haya producido en el marco de una organización dedicada a esta actividad delictiva, además de la agravación correspondiente de las penas individuales se impondrá el comiso de los bienes objeto del delito y de los productos y beneficios obtenidos directa o indirectamente del acto delictivo. Otra vez estamos ante una especificación que trata de evitar lo que, en otro caso, quedaría fuera del ámbito de aplicación del art. 127 CP por ser considerado objeto del delito. Sobraría, por el contrario, la referencia a los productos y beneficios porque ya quedan cubiertos en la noción del comiso de ganancias con carácter genérico.

Al margen de esta precisión, nos encontramos ante un supuesto perfectamente encajable en el art. 3 DM 2005/212 (persona condenada por un delito de blanqueo de bienes cometido en el marco de una organización delictiva) sin la opción, según la legislación vigente, de que el juez decrete el comiso ampliado. Tampoco es de extrañar esta ausencia. Hasta el año 2003, año en que tuvo lugar la última reforma que afectó a estos delitos, la DM más reciente en materia de blanqueo de capitales era la 2001/500, cuyo art. 3 sobre el comiso del valor equivalente ya fue incorporado al $\mathrm{CP}$, como ya se dijo.

\subsection{Tráfico de drogas}

Las reglas especiales sobre el comiso en el ámbito del tráfico de drogas se recogen en el art. $374 \mathrm{CP}$. Existen, no obstante, otras dos menciones al comiso en los artículos 369 y 371 que, por su particularidad, merecen una breve referencia unitaria.

añadido superfluo que no aporta nada, salvo dejar constancia de su sometimiento, además, a las normas especiales del art. $374 \mathrm{CP}$.

${ }_{17} \mathrm{El}$ apartado $4^{\circ}$ del mismo art. 374.1 CP habla igualmente del comiso del valor equivalente cuando, por cualquier circunstancia «no fuera posible el decomiso de los bienes y efectos señalados en el párrafo anterior», es decir, en relación con el apartado $3^{\mathrm{a}}$, el objeto del delito sea de lícito comercio. Es fácil apreciar que este apartado $4^{\mathrm{a}}$ dice lo mismo que el apartado $5^{\text {a }}$ pero con diferentes palabras. Como bien señala Aguado Correa, lo deseable hubiera sido mantener sólo una regla con una mejor redacción. En « La regulación..., op. cit., p. 22. 


\subsubsection{Art. $374 \mathrm{CP}$}

Sobre el contenido de este artículo nos remitimos a lo expuesto en el apartado 2.3.1 en relación al blanqueo de bienes del art. 301.1 CP, segundo párrafo. Recordemos brevemente que considera objeto decomisable al objeto del delito del tráfico de drogas (art. 374.1 CP) e igualmente incorpora el comiso del valor equivalente para esta materia (art. 374.1.5 ), aspecto este último que supone un reiteración innecesaria al art. $127 \mathrm{CP}$ por las razones aducidas en su momento.

\subsubsection{Arts. 369.2 y $371.2 \mathrm{CP}$}

Los delitos contenidos en estos preceptos parten de supuestos similares. El primero regula un tipo agravado del tipo base del tráfico de drogas (art. $368 \mathrm{CP}$ ) cuando concurran una serie de circunstancias descritas en el apartado 1. A nuestros efectos, hay que señalar la $2^{\mathrm{a}}$ (pertenencia a organización dedicada al tráfico de drogas), la $3^{\text {a }}$ (participación del culpable en otras actividades organizadas o cuya ejecución se vea facilitada por la comisión del delito) y la $4^{\mathrm{a}}$ (los hechos se llevan a cabo en establecimientos abiertos al público por los responsables o empleados de los mismos). Por su parte, el art. $371 \mathrm{CP}$ se refiere al llamado tráfico de precursores, pero interesa la agravación que se recoge en su apartado 2 cuando las personas condenadas pertenezcan a una organización dedicada a esta finalidad.

A excepción del supuesto del art. 369.1.4 comisión de un delito de tráfico de drogas en el marco de una organización dedicada a esta actividad delictiva, lo que los acerca a los requisitos del art. 3.1 DM 2005/212 sobre el comiso ampliado, gran ausente de nuestra legislación. Lo curioso de la regulación española vigente es que en estos casos, conforme al art. 369.2, "se impondrá a la organización, asociación o persona titular del establecimiento (...) el comiso de los bienes objeto del delito y de los productos $y$ beneficios obtenidos directa o indirectamente del acto delictivo (...)». Es decir, cuando el delito lo cometa un sujeto perteneciente a una organización delictiva dedicada a tales fines, además del comiso de los efectos, instrumentos y ganancias que recaiga sobre dicha persona física, también la propia organización verá confiscada las ganancias que directa o indirectamente haya obtenido del hecho delictivo, así como de los bienes objeto del delito.

Aunque no es objeto de este trabajo valorar el alcance teórico y práctico de esta disposición, difícilmente puede asumirse que una organización criminal - ¿con o sin personalidad jurídica?- pueda, sin más reflexiones, ser sujeto pasible de un comiso, en la medida en que nuestro Derecho Penal vigente no reconoce la responsabilidad penal de las personas jurídicas ${ }^{18}$.

${ }^{18}$ Hay que matizar el art. 369.2 permite también una pena de multa a la organización criminal -por cierto, ¿bajo qué condiciones y con qué fundamento?-, con lo que podría 


\subsection{Seguridad vial, cohecho y tráfico de influencias}

Aunque poseen un interés particular, las referencias que se hace del comiso en estos ámbitos se alejan de la pretensión de la DM 2005/212 de dar una respuesta eficaz a la criminalidad organizada. El objetivo tanto del art. $381.3 \mathrm{CP}^{19}$, en relación a los delitos contra la seguridad del tráfico, como del art. $431 \mathrm{CP}$, para el tráfico de influencias, es el mismo: permitir que lo que, en todo caso, sería objeto del delito, reciba el tratamiento de instrumento del delito. A quien comete el delito de conducción temeraria con consciente desprecio por la vida de los demás del art. 381, apartados 1 y 2, se le castigará con las penas asignadas a estos delitos y, además el vehículo a motor o el ciclomotor utilizado ser considerará instrumento del delito a los efectos del art. $127 \mathrm{CP}$. Igualmente, las dádivas, presentes o regalos que se ofrezcan para influenciar a las autoridades, funcionarios o particulares, también serán objeto de confiscación.

\section{DECISIÓN MARCO 2005/212 DEL CONSEJO, DE 24 DE FEBRERO DE 2005 RELATIVA AL DECOMISO DE LOS PRODUCTOS, INSTRUMENTOS Y BIENES RELACIONADOS CON EL DELITO}

\section{Introducción}

Partiendo de la idea de que uno de los principales objetivos de la delincuencia organizada es la obtención de beneficios económicos, la DM 2005/212 destaca el hecho de que para luchar eficazmente contra este tipo de delincuencia es necesario reforzar los mecanismos que posibilitan el seguimiento, embargo, incautación y decomiso de los productos del delito. Uno de los principales obstáculos existentes en este ámbito son las divergencias existentes entre las legislaciones internas de los Estados miembros en relación con el blanqueo de capitales y el comiso. Debido a ello, la DM 2005/212 pretendió garantizar que los Estados dispongan de unas normas mínimas comunes que regulen el comiso de forma efectiva. De esta forma, obligó a los Estados miembros a introducir en sus ordenamientos dos aspectos de trascendental importancia para la materia: a) En primer lugar, la posibilidad de confiscar los bienes de una persona condenada en aquellos casos en los que la

pensarse que existiendo sanción penal, le acompañará el comiso. Pero este razonamiento se ve empañado por el mismo motivo aducido en el texto, y es que a pesar de este «peculiar» art. 369.2 permita imponer una multa a la organización, no se ha consagrado -todavía- la capacidad criminal de las personas jurídicas en el sistema penal español. Niega carácter penal a esta multa, otorgándole una naturaleza administrativa, Roca Agapito, L.: El sistema..., op. cit., p. 577.

19 Modificado mediante LO 15/2007, de 30 de noviembre. 
pena correspondiente al delito sea superior a un año de pena privativa de libertad. b) Por otro lado, la DM señalada, estableció que los Estados tenían la obligación de introducir normas dirigidas a mitigar la carga de la prueba en lo que se refiere al origen del patrimonio de una persona condenada por una infracción relacionada con la delincuencia organizada.

Antes de abordar el contenido de la DM 2005/212 cabe poner de manifiesto que, a pesar de que en su art. 6 la DM establecía la obligación de que los Estados miembros tomen las medidas necesarias para adaptar sus ordenamientos internos antes del 15 de marzo de 2007, el legislador español no consiguió incorporar dichas directrices a nuestra normativa penal hasta el año $2010^{20}$.

\section{Decomiso de instrumentos y productos}

El art. 2 DM 2005/212 establecía en su apartado primero que «cada Estado miembro adoptará las medidas necesarias para poder proceder al decomiso, total o parcial, de los instrumentos y productos de infracciones penales que lleven aparejadas penas privativas de libertad de duración superior a un año, o de bienes cuyo valor corresponda a tales productos $\rangle^{21}$.

${ }^{20}$ En efecto, la adecuación de nuestro CP a las exigencias de la DM 2005/212 se materializó por medio de la Ley Orgánica 5/2010, de 22 de junio, por la que se modifica la Ley Orgánica 10/1995, de 23 de noviembre, del Código Penal. En efecto, el apartado VIII del Preámbulo de tal LO establecía lo siguiente:

«De singular importancia resulta la transposición de la Decisión Marco 2005/212/ JAI del Consejo, de 24 de febrero de 2005, relativa al decomiso de los productos, instrumentos y bienes relacionados con el delito. Como se recoge en el instrumento internacional, el principal objetivo de la delincuencia organizada es el beneficio económico y, en consecuencia, el establecimiento de normas comunes relativas al seguimiento, embargo, incautación y decomiso de los productos del delito es objetivo prioritario para conseguir una eficaz lucha contra aquella.

Por ello, se ha completado la regulación existente del comiso encomendando a los jueces y tribunales acordarlo respecto de aquellos efectos, bienes, instrumentos y ganancias procedentes de actividades delictivas cometidas en el marco de una organización o grupo criminal, o bien cuando se trate de delitos de terrorismo, con independencia de si estos últimos se cometen en el seno de una organización o grupo terrorista, tal y como se prevé en la Decisión Marco 2002/475/JAI del Consejo, sobre la lucha contra el terrorismo. Para facilitar la medida, se establece una presunción de procedencia de actividades delictivas cuando el valor del patrimonio sea desproporcionado con respecto a los ingresos legales de todas y cada una de las personas condenadas por delitos cometidos en el seno de la organización o grupo criminal. Asimismo, se faculta a los jueces y tribunales para acordar el comiso cuando se trate de un delito imprudente que lleve aparejado en la ley la imposición de una pena privativa de libertad superior a un año».

${ }^{21}$ El apartado segundo de dicho artículo se refiere a las infracciones fiscales estableciendo que, en relación con esas infracciones «los Estados miembros podrán aplicar 
A su turno, el art. 1 DM establecía el contenido que en su articulado tienen los términos «productos», «bienes», «instrumentos» y «decomiso». Así, el «decomiso» fue definido como «toda pena o medida dictada por un tribunal la raíz de un proceso penal relativo a una o varias infracciones penales, que tenga como consecuencia la privación definitiva de algún bien»; por su parte, un «instrumento» de la infracción penal es «todo bien utilizado o destinado a ser utilizado, de cualquier forma, total o parcialmente, para la comisión de una o varias infracciones penales»; mientras que «producto» de la infracción penal es «todo beneficio económico derivado de una infracción penal» pudiendo consistir en «cualquier clase de bienes». En las tres definiciones nos aparece el término «bienes», al que también se dota de contenido concreto en dicho artículo al decir que se puede tratar de «los bienes de cualquier clase, materiales o inmateriales, muebles o inmuebles, así como los actos jurídicos o documentos que acrediten la titularidad $u$ otros derechos sobre tales bienes $\rangle^{22}$.

El Convenio del Consejo de Europa de 8 de noviembre de 1990 relativo al blanqueo, seguimiento, embargo y decomiso de los productos del delito establecía en su art. 2 la posibilidad de formular reservas en relación con el comiso en delitos relativos al blanqueo de capitales, posibilidad a la que se acogieron algunos Estados miembros. Con el objetivo de armonizar las regulaciones internas de los Estados y así intensificar la lucha contra la delincuencia organizada, la DM 2001/50023 en su art. 1 instó a los Estados miembros a «adoptar las medidas necesarias a fin de no formular ni mantener ninguna reserva» en relación con el art. 2 del Convenio de 1990 citado «cuando los delitos lleven aparejada una pena privativa de libertad o medida de seguridad de duración máxima superior a un año» y el art. 6.1 de dicha DM daba de plazo hasta el 31 de diciembre de 2002 para que los Estados miembros llevaran a cabo las modificaciones necesarias en sus regulaciones internas. A la vista de que no todos los Estados miembros habían cumplido dicha obligación, la DM 2005/212 reiteró en su art. 2 la necesidad de llevar a cabo dichas modificaciones de modo que todas las regulaciones internas contemplen la

procedimientos distintos de los penales con el fin de privar al autor del producto de la infracción». No vamos a tratar este punto por exceder el objeto de este trabajo.

22 Estas definiciones coinciden con las utilizadas en otros instrumentos comunitarios como en el art. 1 del Convenio del Consejo de Europa de 8 de noviembre de 1990 relativo al blanqueo, seguimiento, embargo y decomiso de los productos del delito y el art. 3 de la DM 2001/500 de 26 de junio de 2001 relativa al blanqueo de capitales, la identificación, seguimiento, embargo, incautación y decomiso de los instrumentos y productos del delito (dicho art. 3 se remite al art. 1 del Convenio de 1990).

${ }^{23}$ Decisión Marco 2001/500/JAI del Consejo de 26 de junio de 2001 relativa al blanqueo de capitales, la identificación, seguimiento, embargo, incautación y decomiso de los instrumentos y productos del delito (DO L 182 de 5.7.2001). 
posibilidad de decomisar los productos e instrumentos de todas las infracciones penales que lleven aparejadas penas privativas de libertad de duración superior a un año ${ }^{24}$.

Por su parte, el art. 2.1 in fine instó a los Estados miembros a adoptar las medidas necesarias para poder llevar a cabo el comiso, no de los instrumentos y productos del delito, sino de «bienes cuyo valor corresponda a tales productos». Esta referencia al conocido como «comiso del valor equivalente» también se encontraba prevista en el art. 3 de la DM 2001/500 que exigía a los Estados miembros adoptar las medidas necesarias para permitir «al menos en los casos en que dichos productos no puedan ser aprehendidos, el decomiso de bienes cuyo valor corresponda al de los productos $\rangle^{25}$. Hay que destacar que la propuesta de regulación del comiso de valor equivalente realizada en dicha DM parecía referirse únicamente al valor equivalente de los productos, y no al valor equivalente de los instrumentos. Ahora bien, como se verá más adelante, la técnica legislativa adoptada por los redactores de esta DM -a diferencia de la utilizada por el legislador español de 2015, en la que prevé la posibilidad de proceder al decomiso del valor equivalente de los instrumentos utilizados para la comisión del delito- resulta compatible con aquella propuesta doctrinal que entiende que el comiso tiene una naturaleza jurídica estrictamente extrapenal. Como hemos señalado anteriormente, el art. 2 reiteraba, también en este punto, las obligaciones establecidas en la DM 2001/500 debido a su falta de cumplimiento por parte de algunos Estados.

\section{Potestad de decomiso ampliada}

La potestad de decomiso ampliada, a la que en adelante nos referiremos como «comiso ampliado», se regula en el art. 3 DM 2005/212 y es el punto más importante de la DM, debido a la novedad de dicha figura.

${ }^{24}$ Hay que señalar que este art. 2 se refiere únicamente a penas privativas de libertad, no a «pena privativa de libertad o medida de seguridad» como hacía la DM 2001/500 y, además, establece que dichas penas tengan una "duración superior a un año», lo que parece referirse a la pena concreta establecida en la sentencia, como veremos más adelante.

${ }^{25}$ La redacción completa del art. 3 de la DM 2001/500 es la siguiente: «cada Estado miembro adoptará las medidas necesarias para que su legislación y procedimientos sobre decomiso del producto del delito también permitan, al menos en los casos en que dichos productos no pueden ser aprehendidos, el decomiso de bienes cuyo valor corresponda al de los productos, tanto en procedimientos estrictamente nacionales como en procedimientos incoados a petición de otro Estado miembro, incluidas las solicitudes para la ejecución de órdenes de decomiso procedentes del extranjero. No obstante, los estados miembros podrán excluir el decomiso de bienes de un valor que corresponda al producto del delito en los casos en que dicho valor sea inferior a 4000 euros». 
En efecto, la figura en cuestión consiste, básicamente, en la posibilidad de confiscar los bienes de una persona condenada por cometer un delito; pero no se trata de decomisar los instrumentos y productos de dicho delito (esto ya es posible mediante el comiso de instrumentos y productos), sino aquellos bienes que posea el condenado y que deriven de actividades delictivas distintas a aquella por la que ha sido condenado.

No es la primera vez que en el ámbito de la Unión Europea se pretende regular el comiso ampliado. Ya en el año 2000 el Consejo planteó la necesidad de estudiar si es necesario un instrumento que posibilite la mitigación de la carga de la prueba en los supuestos $\operatorname{citados}^{26}$ y también en el seno de las Naciones Unidas nos encontramos con referencias a esta posibilidad; la Convención de las Naciones Unidas de 12 de diciembre de $2000^{27}$ señala que los Estados parte pueden considerar la "posibilidad de exigir a un delincuente que demuestre el origen lícito del presunto producto del delito o de otros bienes expuestos a decomiso en la medida en que ello sea conforme con los principios de su Derecho interno y con la índole del proceso judicial».

El objetivo de esta figura es, como se señala en los motivos de la DM, «la posibilidad de mitigar la carga de la prueba en lo que se refiere al origen del patrimonio de una persona condenada por una infracción relacionada con la delincuencia organizada». Más adelante volveremos sobre esta cuestión de la carga de la prueba.

Básicamente, para poder aplicar el comiso ampliado, deben de concurrir dos elementos: una condena por una infracción penal de las enumeradas en el art. $3.1 \mathrm{y}$, además, alguno de los tres supuestos recogidos en el art. 3.2. A continuación vamos a desarrollar cada uno de estos elementos para, posteriormente, plantear algunas cuestiones problemáticas que se suscitan .

No hay que olvidar que el art. 3 se refiere a las medidas que «como mínimo» tienen que adoptar los Estados miembros, por lo que no hay ningún problema en que los ordenamientos internos regulen esta figura dando cabida a más supuestos de los recogidos en la DM.

\subsection{Características de la infracción}

Como ya hemos adelantado, la DM recoge en el art. 3.1 las características que tiene que tener la infracción penal por la que ha sido condenada una

${ }^{26}$ Recomendación $n^{\text {o }} 19$ del plan de acción de 2000: prevención y control de la delincuencia organizada -Estrategia de la Unión Europea para el comienzo del nuevo milenio (DO C 124 de 3.5.2000)

27 Art. 12 sobre decomiso e incautación, de la Convención de las Naciones Unidas contra la Delincuencia Organizada Transnacional, de 12 de diciembre de 2000. 
persona para poder privarle de sus bienes aplicando la figura del comiso ampliado que son las siguientes:

\subsubsection{La infracción tiene que cometerse en el marco de una organización delictiva}

El art. 3.1.a) nos remite a la definición de organización delictiva contenida en el art. 1 de la Acción Común 98/733 ${ }^{28}$ según la cual «se entenderá por «organización delictiva» una asociación estructurada de más de dos personas, establecida durante un cierto periodo de tiempo, y que actúe de manera concertada con el fin de cometer delitos sancionables con una pena privativa de libertad de un máximo de al menos cuatro años como mínimo o con una pena aún más severa, con independencia de que esos delitos constituyan un fin en sí mismos o un medio de obtener beneficios patrimoniales y, en su caso, de influir de manera indebida en el funcionamiento de la autoridad pública».

3.1.2. La infracción cometida tiene que estar prevista en alguna de las siguientes DM

- DM 2000/383, de 29 de mayo de 2000, sobre el fortalecimiento de la protección, por medio de sanciones penales y de otro tipo, contra la falsificación de moneda con miras a la introducción del euro ${ }^{29}$.

- DM 2001/500, de 26 de junio de 2001, relativa al blanqueo de capitales, la identificación, seguimiento, embargo, incautación y decomiso de los instrumentos y productos del delito ${ }^{30}$.

- DM 2002/629, de 19 de julio de 2002, relativa a la lucha contra la trata de seres humanos ${ }^{31}$.

- DM 2002/946, de 28 de noviembre de 2002, destinada a reforzar el marco penal para la represión de la ayuda a la entrada, a la circulación y a la estancia irregulares ${ }^{32}$.

- DM 2004/68, de 22 de diciembre de 2003, relativa a la lucha contra la explotación sexual de los niños y la pornografía infantili3.

28 Acción Común 98/733/JAI, de 21 de diciembre de 1998, relativa a la tipificación penal de la participación en una organización delictiva en los Estados miembros de la Unión Europea (DO L 351 de 29.11.1998).

${ }^{29}$ DO L 140 de 14.6.2000

${ }^{30}$ DO L 182 de5.7.2001

31 DO L 203 de 1.8.2002

${ }^{32}$ DO L 328 de 5.12.2002

${ }^{33}$ DO L 13 de 20.1.2004 
- DM 2004/757, de 25 de octubre de 2004, relativa al establecimiento de disposiciones mínimas de los elementos constitutivos de delitos y las penas aplicables en el ámbito del tráfico ilícito de drogas ${ }^{34}$.

3.1.3. La infracción está prevista en la DM 2002/475, de 13 de junio de 2002, sobre la lucha contra el terrorismo ${ }^{35}$.

3.1.4. Que la infracción según las DM citadas se castiguen con penas de prisión de al menos cuatro años en su grado máximo si se trata de blanqueo de capitales o con penas de prisión de al menos entre cinco y diez años en su grado máximo en los demás casos.

3.1.5. Que la infracción sea de tal naturaleza que pueda generar un beneficio económico.

\subsection{Supuestos de aplicación del comiso ampliado}

El art. 3.2 enumera los tres supuestos en los cuales, si una persona ha sido condenada por una infracción de las arriba citadas, tiene que ser posible proceder al comiso ampliado de sus bienes:

3.2.1 cuando un órgano jurisdiccional nacional, basándose en hechos concretos, esté plenamente convencido de que los bienes a los que se quiere aplicar el comiso ampliado provienen de actividades delictivas llevadas a cabo por el condenado durante un período anterior a la condena por alguna de las infracciones arriba citadas.

3.2.2. o cuando un órgano jurisdiccional nacional, basándose en hechos concretos, esté plenamente convencido de que los bienes a los que se quiere aplicar el comiso ampliado provienen de actividades delictivas similares llevadas a cabo por el condenado durante un período anterior a la condena por alguna de las infracciones arriba citadas.

3.2.3. o cuando se tenga constancia de que el valor de la propiedad es desproporcionado con respecto a los ingresos legales del condenado y un

\footnotetext{
${ }^{34}$ DO L 335 de 11.11.2004

${ }^{35}$ DO L 164 de 22.6.2002
} 
órgano judicial nacional, basándose en hechos concretos, esté plenamente convencido de que dichos bienes provienen de la actividad delictiva del condenado

\subsection{Cuestiones que suscita el decomiso ampliado}

Vamos a referirnos a continuación a algunas cuestiones problemáticas que plantean la lectura de los apartados 1 y 2 del art. 3 que estamos comentando.

En primer lugar, hay que señalar que, tal y como establece el apartado primero, tiene que haber una condena por alguna de las infracciones recogidas en las DM citadas. Esto quiere decir que los tipos penales concretos que dan lugar al comiso ampliado dependerán del modo en que cada Estado miembro incorpore dichas DM en su ordenamiento interno.

En segundo lugar, los dos primeros supuestos establecen que los bienes objeto de comiso ampliado tienen que provenir de actividades delictivas desarrolladas «durante un periodo anterior a la condena», pero no establecen un límite, por lo que, en principio, parece posible decomisar bienes provenientes de actividades delictivas llevadas a cabo en cualquier momento con el único límite de que se hayan realizado antes de la condena (no antes de cometer la infracción por la que ha sido condenado).

En la práctica pueden surgir cuestiones que merecen una reflexión, como por ejemplo, ¿qué ocurre si la actividad delictiva es una infracción penal ya prescrita? Quizás pueda entenderse como límite la referencia que se hace en ambos párrafos a que el órgano jurisdiccional lo considere «razonable» a la vista de las circunstancias del caso concreto. De todos modos, esta problemática, como se verá más adelante, ha sido resuelta por el legislador penal español de 2015 al haberse hecho expresa referencia al hecho de que, esta clase de decomiso no será acordada cuando las actividades delictivas de las que provengan los bienes o efectos hubieran prescrito o hubieran sido ya objeto de un proceso penal resuelto por sentencia absolutoria o resolución de sobreseimiento ${ }^{36}$.

En tercer lugar, se señala que los bienes decomisados provengan de «actividades delictivas» y en el segundo supuesto, se hace referencia a actividades delictivas «similares», pero no se especifica nada más al respecto. Podría interpretarse que en el primer párrafo se refiere a bienes que provienen de

${ }^{36}$ En efecto dicha previsión se incluye en el nuevo artículo 127 bis del CP, que fue introducido en nuestra legislación penal por medio del número sesenta y dos del artículo único de la LO 1/2015, de 30 de marzo, por la que se modifica la LO 10/1995, de 23 de noviembre, del Código Penal. 
actividades delictivas del mismo tipo que la que ha dado lugar a la condena, es decir, alguna de las incluidas en el primer apartado, y en el segundo, al referirse a «similares» se incluyen otras infracciones distintas a la que es objeto de condena, pero también recogida en el apartado primero o bien podía interpretarse en otro sentido, entendiendo que «similares» hace referencia a infracciones no recogidas en el apartado primero pero semejantes a ellas. En cualquier caso, la duda en cuestión se ha despejado en la nueva redacción del CP español, al haberse hecho referencia únicamente, en los distintos apartados referidos al comiso ampliado, a las actividades «delictivas», obviándose la referencia a las actividades delictivas «similares».

Otro aspecto a tener en cuenta en este punto es si esas actividades delictivas diferentes a las que motivan la condena tienen que haberse llevado a cabo en el marco de una organización delictiva o no, puesto que los tres supuestos no dicen nada al respecto. Habría sido conveniente, desde luego, que la DM haga expresa mención a este aspecto a fin de esclarecer esta duda que, desde nuestro punto de vista, parece encontrar solución en la interpretación de que dicha vinculación con organizaciones delictivas debe exigirse, puesto que la DM reitera constantemente que su objetivo es armonizar las legislaciones internas en relación con la delincuencia organizada y la interpretación contraria no parece que tenga mucho sentido.

En cuarto lugar, para aplicar el comiso ampliado, el órgano judicial tiene que estar plenamente convencido de que los bienes provienen de actividades delictivas, es decir, llegar al convencimiento pleno de que la persona condenada ha cometido con anterioridad a la condena otras infracciones penales que no están siendo objeto de proceso penal alguno, puesto que en ese caso dicho proceso finalizaría, en su caso, con una condena y se decretaría el comiso de instrumentos y productos correspondiente. Entonces, después de la aplicación del comiso ampliado, ¿se perseguirán esas infracciones penales iniciándose los correspondientes procesos? Y si resulta condenado por ellas, ya no se podrá decretar el comiso al menos de los productos, puesto que ya han sido previamente decomisados al aplicar el comiso ampliado. Y si se le absuelve, ¿se devolverá lo decomisado? ¿o se le indemnizará si ya se le ha dado destino? La reforma penal operada en el año 2015 ha abordado esta cuestión sin dar respuesta a todas estas interrogantes. En efecto, en el apartado número 4 del art. 127 bis se establece que, en caso de una posterior condena, se valorará el alcance del decomiso anteriormente acordado en el momento de resolver el comiso en el nuevo procedimiento. Como se ve, quedan diversas dudas por resolver.

En quinto lugar, el art. 3.2 establece la posibilidad de decomisar el patrimonio de un condenado por alguno de los delitos recogidos en el art. 3.1 si el mismo es desproporcionado, teniendo en cuenta cuáles son los ingresos legales de esa persona, y el juez o tribunal competente está plenamente convencido de 
que proviene de actividades delictivas llevadas a cabo por el condenado. Este supuesto plantea una mitigación de la carga de la prueba a la hora de determinar el origen de algunos patrimonios que, como ya hemos mencionado anteriormente, es uno de los objetivos de la DM 2005/212. Conscientes de que esto puede suponer un conflicto con los principios básicos de los ordenamientos de algunos Estados miembros, principalmente en relación con la presunción de inocencia, el art. $5 \mathrm{DM}$ establece que «la presente Decisión no tendrá el efecto de modificar la obligación de respetar los derechos y principios fundamentales, incluida en particular la presunción de inocencia, consagrados en el articulo 6 del Tratado de la Unión Europea» y el art. 4 señala que «cada Estado miembro adoptará las disposiciones necesarias para garantizar que las partes interesadas afectadas por las medidas a las que se refieren los artículos 2 y 3 dispongan de vías de recurso efectivas para defender sus derechos $»^{37}$.

\subsection{Otras previsiones sobre el comiso ampliado}

El apartado 3 del art. $3 \mathrm{DM}$ dice que «cada Estado miembro podrá estudiar además la posibilidad de adoptar las medidas necesarias que le permitan proceder, conforme a las condiciones fijadas en los apartados 1 y 2, al decomiso, total o parcial, de bienes adquiridos por los allegados de la persona de que se trate y de bienes transferidos a una persona jurídica sobre la que la persona de que se trate ejerza un control efectivo individualmente o junto cono sus allegados. La misma regla será de aplicación si la persona interesada recibe una parte considerable de los ingresos de la persona jurídica».

Por último, en el apartado 4 se deja a los Estados miembros la posibilidad de recurrir a procedimientos distintos de los penales para llevar a cabo el comiso.

\section{EL IMPACTO DE LA DM 2005/212 EN LA REFORMA PENAL DE 2010}

\section{Introducción}

Como se ha indicado, la regulación penal española del comiso, a pesar de la ampliación a que se vio sometida con la reforma del CP de 2003, tal vez

37 También en los motivos de la DM nos encontramos con varias referencias a este punto que evidencian los problemas que pueden plantearse al transponer esta disposición a los ordenamientos internos. El motivo 11, por ejemplo dice que «la presente Decisión marco no impide a ningún Estado miembro aplicar sus principios fundamentales en materia de garantías procesales, en particular la presunción de inocencia, los derechos de propiedad, libertad de asociación, libertad de prensa y libertad de expresión en otros medios de comunicación». 
proporcionaba una normativa adecuada para dar respuesta a la delincuencia tradicional, pero no aportaba mecanismos suficientes para enfrentarse a uno de los fenómenos que más dificultades de persecución y sanción generan al Derecho Penal: la criminalidad organizada ${ }^{38}$. Como hemos tenido ocasión de comprobar, el CP español cumplía parcialmente con las disposiciones que emanan de las instituciones comunitarias, en concreto y con matices, con el art. 2 DM 2005/212, en lo que a comiso de efectos y productos se refiere (en terminología del CP, efectos, instrumentos y ganancias). Pero no ocurre otro tanto con el comiso ampliado del art. 3 de dicha DM a la hora de confiscar el llamado «patrimonio criminal» que obtenido por una actividad delictiva continuada en el seno de una organización delictiva.

En realidad, el legislador español no ha estado ocioso. Con fecha de 13 de julio de 2006 se aprobó por al Consejo de Ministros un Anteproyecto de Reforma del CP; reforma motivada precisamente por la necesidad, entre otros aspectos, de adaptar la normativa penal vigente a las exigencias de armonización de los ordenamientos jurídico-penales estatales surgidas en el ámbito comunitario e internacional. Tras los pertinentes informes dictados por el Consejo General del Poder Judicial ${ }^{39}$ y del Consejo Fiscal ${ }^{40}$, se elevó al Congreso el texto del Proyecto de reforma ${ }^{41}$ (en adelante PCP), que finalmente dio lugar a que en el año 2010 se publique y entre en vigor la segunda modificación en materia de comiso que ha tenido nuestro $\mathrm{CP}^{42}$. Cabe recordar que, durante la tramitación de esta reforma se rechazó una enmienda presentada a la totali$\mathrm{dad}^{43}$. De todos modos, y como ya se ha indicado, con la modificación de la regulación del comiso en el año 2010, España incumplió el plazo dispuesto en la DM 2005/212 de incorporación de las previsiones sobre el comiso, tanto de efectos y productos como ampliado, que era el 15 de marzo de 2007.

Aun con todo, debemos detenernos en las modificaciones que incluye la reforma penal de 2010 puesto que con estas sí pretendió dar cumplimiento a

${ }^{38}$ En el mismo sentido, Choclán Montalvo, J.A.: El patrimonio criminal..., op. cit., pp. 15-16.

39 De 27 de octubre de 2006.

40 De 21 de noviembre de 2006.

${ }^{41}$ BOCG-Congreso de los Diputados, serie A, núm.119-1, de 15 de enero de 2007. En materia de regulación de comiso, aspecto al que se circunscribe este trabajo, el CP (reforma de 2010) no presenta ninguna modificación respecto del Proyecto. Por eso, valen igualmente las observaciones emitidas sobre esta regulación por los informes preceptivos del Consejo General del Poder Judicial y del Consejo Fiscal.

${ }^{42}$ En efecto, dicha modificación se produce en virtud de lo dispuesto por la Ley Orgánica 5/2010, de 22 de junio, por la que se modifica la Ley Orgánica 10/1995, de 23 de noviembre, del Código Penal.

43 Diario de Sesiones del Congreso de los Diputados, VIII Legislatura, año 2007, núm. 281, de 13 de septiembre de 2007. 
las disposiciones comunitarias. Las novedades que incorpora se ciñen, fundamentalmente, a la posibilidad de acordar el comiso también para delitos imprudentes y en el comiso ampliado. Antes de eso, es necesario detenernos brevemente en una cuestión que, aunque no se diga expresamente ni en la regulación genérica ni específica del comiso, incide directamente en su aplicación, como es la consagración de la responsabilidad penal de las personas jurídicas en el CP.

\section{Regulación general (arts. 127 y $128 \mathrm{CP}$ )}

\subsection{Comiso y personas jurídicas}

Una de las novedades más trascendentes que supuso la reforma penal de 2010 para el Derecho Penal español fue, sin duda, el reconocimiento de la responsabilidad penal de las personas jurídicas, que pasan a convertirse, junto a las personas físicas, en sujetos de imputación jurídico-penal. Con esta consagración se busca acomodar la regulación penal española a los numerosos instrumentos internacionales que la han venido proponiendo ${ }^{44}$, al margen de los problemas dogmáticos que inevitablemente plantea con nuestra Teoría del Delito, construida sobre la base de la actuación del ser humano individual ${ }^{45}$.

El sistema penal de las personas jurídicas se reguló en un nuevo art. 31 bis y se completó con las disposiciones de los arts. 33.7, 129 y $130 \mathrm{CP}$ (insistimos, en su versión de 2010) en materia de penas imponibles a las personas jurídicas, consecuencias accesorias y extinción de la responsabilidad penal,

${ }^{44}$ En tales términos se expresa la propia Exposición de Motivos del Proyecto de reforma CP que da origen a la modificación de 2010, al justificar este cambio de regulación: "Incide luego la reforma en el importante problema de la responsabilidad penal de las personas jurídicas, cuya regulación penal encierra importantes dificultades generadas, como fácilmente se comprende, por el que hasta ahora pareciera infranqueable principio societas delinquere non potest. Pero la satisfacción de las obligaciones dimanantes de un amplio abanico de Decisiones Marco, como son por ejemplo las DM 2005/667, 2005/222, 2004/757, 2004/68, obliga a superar esa dificultad procurando además el máximo respeto a las garantías acumuladas por el derecho penal de la culpabilidad. (...) La coincidencia internacional en lo ineludible de que los sistemas penales acogieran esa clase de responsabilidad, ha venido impuesta, como fácilmente se puede comprender, especialmente por la necesidad de robustecer el marco jurídico en que se puede desarrollar con eficacia y garantía el principio de libre empresa, que ha de desarrollar su eficacia en un espacio que supera ampliamente el marco territorial y económico de los Estados».

${ }^{45}$ Por eso, sin negar la necesidad de incluir a las personas jurídicas en el sistema penal español, si estas previsiones se convierten finalmente en derecho vigente necesitarán, en todo caso, una profunda reflexión, doctrinal y jurisprudencial, en cuanto al fundamento, contenido del sistema que se propone. 
respectivamente. No obstante, a efectos de este trabajo, únicamente vamos a detenernos en las implicaciones que este reconocimiento supone para la aplicación de la versión de 2010 del art. 127. Si persona física y persona jurídica pueden ser ambas castigadas por la comisión de un delito, también a esta última, a falta de otra previsión expresa, le son aplicables las reglas generales y específicas sobre el comiso. Si bien, hay que tener en cuenta que esto no vale para cualquier delito, sino únicamente para aquellos a los que el CP adscribe el sistema de imputación a la persona jurídica ${ }^{46}$. De ahí se deducen las siguientes hipótesis, atendiendo al juego simultáneo o exclusivo de responsabilidad penal entre persona física y jurídica ${ }^{47}$ :

- Puede suceder que sólo la persona física sea castigada penalmente, bien porque se trata de un delito no circunscrito al ámbito de aplicación del art. 31 bis CP, bien porque, aun siendo un delito imputable a la persona jurídica, esta no es responsable conforme a las condiciones del mencionado precepto. En estos casos, la persona jurídica, al no ser sancionada penalmente, no es destinataria directa del comiso; pero puede verse afectada, indirectamente, por lo dispuesto en el último inciso del art. 127.1 CP (reforma de 2010). Es decir, cuando los efectos, instrumentos o ganancias hayan sido transmitidos a la titularidad de una persona jurídica. Aunque en tal hipótesis habrá que probar la buena o mala fe del ente, algo que casa mal con el propio concepto de «persona jurídica».

- También puede ocurrir que tanto persona física como jurídica sean penalmente responsables según los criterios del art. 31 bis CP (reforma de

${ }^{46}$ El CP (reforma de 2010) ha instaurado un sistema de numerus clausus al que ciñe la responsabilidad penal de la persona jurídica, tal como afirma el comienzo del art. 31 bis, apartado 1 ( «En los supuestos previstos en este Código...»). En concreto, se prevé para los siguientes delitos: art. 162, delitos relativos a la manipulación genética; art. 189.8, prostitución de menores; art. 264.4, daños a datos contenidos en soportes informáticos; art. 288 delitos contra la propiedad intelectual, industrial y contra el mercado y los consumidores; art. 294, obstaculización a las labores de inspección y supervisión de la Administración; art. 297 bis, creación o mantenimiento de sociedades ficticias; art. 302.2, tipo agravado del blanqueo de bienes; art. 310 bis, delitos contra la Hacienda Pública y la Seguridad Social, art. 318, delitos contra los derechos de los trabajadores, art. 319.3, delitos sobre la ordenación del territorio; art. 327, delitos contra el medio ambiente; art. 366, delitos contra la salud pública (sólo arts. 364 y 365); arts. 369.2, 369 bis, y 371, tráfico de drogas; art. 399 bis, falsificación, copia o reproducción de tarjetas de crédito o débito o cheques de viaje; art. 430, tráfico de influencias; art. 445.2, delitos de corrupción en las transacciones comerciales internacionales; art. 520, asociación ilícita; art. 569, depósito de armas, municiones o explosivos.

47 Simplemente dejaremos apuntadas estas hipótesis; no vamos a adentrarnos en los problemas específicos que se derivan particularmente en cada una de ellas. 
2010). En esta hipótesis la pena de una y otra iría acompañada, directamente, del comiso (sólo para los delitos en que pueda ser responsable la persona jurídica, claro está). Aquí pierde sentido lo dicho en el apartado a), puesto que, en todo caso, los efectos, instrumentos y ganancias (e incluso para el comiso ampliado) serían decomisables como acompañamiento a la pena impuesta.

- La última hipótesis posible sería que sólo la persona jurídica, dentro del ámbito de aplicación de su responsabilidad, fuera condenada penalmente ${ }^{48}$. En principio, valdría lo dicho en la letra a) pero invirtiendo los términos. La pena a la entidad vendría acompañada del comiso y, en caso de que se hubieran transmitido los bienes a la persona individual, podría operar el último inciso del art. 127.1 CP (2010), con la salvedad de la buena fe del sujeto. No obstante, también podría entrar en juego el apartado 4 del art. $127 \mathrm{CP}$ en relación a la persona física, de tal manera que el órgano judicial podría acordar el comiso aun cuando no existiera pena para el individuo por estar exento de responsabilidad o haberse extinguido esta.

Destacaremos, para finalizar, que el CP 2010 mantuvo, aunque con una nueva redacción, las consecuencias accesorias del art. $129 \mathrm{CP}$, que conviven con el art. 31 bis. Ante esta inexplicable relación entre penas y consecuencias accesorias, se nos plantea la siguiente pregunta ${ }^{49}$ : si a una organización, con o sin personalidad jurídica, no se le impone una pena pero sí una consecuencia accesoria, ¿cabe acompañarla de comiso? En principio creemos que la respuesta debiera ser no, puesto que ya el comiso es una consecuencia accesoria. No obstante, esto puede ser válido para la actual regulación de las consecuencias accesorias, pero la pregunta se vuelve más compleja cuando hablamos de unas medidas que coinciden en su contenido con las penas previstas para la persona jurídica en el art. $33.7 \mathrm{CP} 2010$ y no se han aclarado los criterios que hacen que, ante la comisión de un mismo delito, se apliquen unas reacciones como penas según el art. 31 bis o, siendo las mismas, como consecuencias accesorias según el art. 129 CP.

${ }^{48} \mathrm{El}$ art. 31 bis CP (reforma de 2010) no acoge expresamente esta posibilidad de castigo autónomo de la persona jurídica. No obstante, y a falta de un estudio en rigor sobre el tema, podría plantearse esta variante, conforme al sistema consagrado en el CP, si se admitiera que las causas que excluyen, al menos, la culpabilidad del sujeto individual no impide apreciar la responsabilidad penal de la entidad.

${ }^{49}$ Nos parece inexplicable porque la Exposición de Motivos del Proyecto de reforma del CP que da origen a la reforma penal de 2010 no ofrece argumentos convincentes para seguir manteniendo estas consecuencias accesorias una vez proclamada la responsabilidad penal de las personas jurídicas. 


\subsection{El comiso en los delitos imprudentes}

El CP (reforma de 2010) dio una nueva redacción al apartado 2 del art. 127 , de modo que los anteriores apartados 2,3 y 4, pasaron a ser los apartados 3,4 y 5 , sin sufrir ninguna modificación.

Este nuevo apartado segundo ya contempló la posibilidad de acordar el comiso cuando el delito cometido sea un delito imprudente y la pena impuesta sea una pena privativa de libertad superior a un año. Se trata, por lo tanto, de dar cumplimiento al art. 2 de la DM 2005/212, puesto que, como ya se ha visto en apartados anteriores, los bienes de los condenados por un delito imprudente a más de un año de prisión no pueden ser decomisados al limitarse el antiguo art. 127 a los delitos dolosos.

Conviene señalar que, mientras el comiso en el caso de los delitos dolosos es obligatorio, tal y como señala el art. 127.1 («llevará»), en el caso de los imprudentes castigados con más de un año de pena privativa de libertad, es potestativo («podrá») y serán los jueces o tribunales competentes en cada caso los encargados de valorar las circunstancias concurrentes y determinar qué es lo más adecuado ${ }^{50}$.

Este comiso tiene el mismo alcance que el que se lleva a cabo en los delitos dolosos (efectos, bienes, medios, instrumentos y ganancias), y también se contempla expresamente la posibilidad de confiscar los bienes «cualquiera que sean las transformaciones que hubieran podido experimentar ${ }^{51}$.

\subsection{El comiso ampliado}

El CP (reforma de 2010) introdujo en nuestro ordenamiento la figura del comiso ampliado contemplada en el art. 3 de la DM 2005/212 y para ello añade el siguiente párrafo al art. 127.1: «El Juez o Tribunal deberá ampliar el decomiso a los efectos, bienes, instrumentos y ganancias procedentes de actividades delictivas cometidas en el marco de una organización o grupo criminal o terrorista, o de un delito de terrorismo. A estos efectos se entenderá que proviene de la actividad delictiva el patrimonio de todas y cada una de las personas condenadas por delitos cometidos en el seno de la organización o grupo criminal o terrorista o por un delito de terrorismo cuyo valor sea desproporcionado con respecto a los ingresos obtenidos legalmente por cada una de dichas personas».

El objetivo de esta figura fue confiscar, no sólo los instrumentos y productos utilizados o derivados de la comisión del delito por el que una

${ }^{50}$ A tales efectos, el órgano judicial deberá guiarse, con mayor motivo que en los delitos dolosos, por los criterios establecidos en el art. 128 CP (reforma de 2010).

${ }^{51}$ En relación con estos aspectos, nos remitimos a lo visto en el punto 3.2. sobre el «comiso de valor equivalente». 
persona ha sido condenada, sino también otros bienes procedentes de actividades delictivas distintas a las que han dado lugar a la condena para evitar cualquier tipo de beneficio económico derivado de la vinculación a una organización criminal. A continuación desarrollaremos el contenido de los requisitos que estableció el CP (reforma de 2010) para aplicar el comiso ampliado y comentaremos los puntos problemáticos.

\subsubsection{Requisitos y contenido del comiso ampliado}

Si bien en el Proyecto de reforma, tal y como ocurrió con el comiso en relación con delitos imprudentes, la aplicación del comiso ampliado se configuraba como una facultad que tiene el Juez o Tribunal correspondiente, y no como una obligación; en la versión definitiva del texto, esto es, la que finalmente fue adoptada por el legislador de 2010, esta modalidad de comiso era, en efecto, una obligación («El Juez o Tribunal deberá ampliar el decomiso...»).

Para poder aplicar este comiso ampliado era necesario haber sido condenado por un delito cometido «en el marco de una organización o grupo criminal o terrorista, o de un delito de terrorismo» ${ }^{52}$. La DM 2005/212 se refiere al mismo requisito, pero no define qué se entiende por organización delictiva, sino que se remite a la definición dada por la Acción Común 98/73353. Cabe resaltar que la definición de organización o grupo criminal fue incorporada, por primera vez, en la misma reforma de 2010. En efecto, con base en la redacción de los artículos 570 bis y 570 ter, se entendía que una organización criminal es la «agrupación formada por más de dos personas con carácter estable o por tiempo indefinido, que de manera concertada y coordinada se repartan diversas tareas o funciones con el fin de cometer delitos, así como de llevar a cabo la perpetración reiterada de faltas», mientras que un grupo criminal es el resultante de la «unión de más de dos personas que, sin reunir alguna o algunas de las características de la organización criminal definida en el artículo anterior, tenga por finalidad o por objeto la perpetración concertada de delitos o la comisión concertada y reiterada de faltas».

La DM 2005/212, tal y como ya se comentó, contempla el comiso ampliado para aquellos supuestos en los cuales el delito cometido en el seno de una organización criminal sea alguno de los enumerados en su art. 3.1 ${ }^{54}$.

${ }^{52}$ Aunque el art 3 DM 2005/212 se refiere a «organización delictiva», se entiende que son términos sinónimos.

53 Véase la definición recogida en la página 6.

${ }^{54}$ Relativas a delitos de falsificación de moneda; blanqueo de capitales; trata de seres humanos; entrada, circulación y estancia irregulares; explotación sexual de niños y pornografía infantil; tráfico ilícito de drogas; terrorismo. 
El CP (reforma de 2010) dio mayor contenido al comiso ampliado puesto que se refiere a «cualquier delito cometido en el seno de la organización o grupo criminal o terrorista o por un delito de terrorismo cuyo valor sea desproporcionado con respecto a los ingresos obtenidos legalmente por cada una de dichas personas». Esta mayor amplitud en la regulación no supone ningún problema porque, como hemos dicho en más de una ocasión, la DM 2005/212 establece unos límites mínimos, sin que exista obstáculo para que los Estados miembros realicen una regulación más amplia de esta figura.

Aunque la redacción pudo dar lugar a alguna duda, parece evidente que el objetivo de este comiso ampliado era el de confiscar el patrimonio de las personas condenadas, no de la organización ${ }^{55}$. Asimismo, el patrimonio que se decomisa tiene que provenir de actividades delictivas llevadas a cabo en el seno de la organización o grupo criminal (...).

Por lo tanto, el comiso ampliado consiste en confiscar a una persona condenada por cometer un delito en el seno de una organización delictiva bienes procedentes, no del delito por el que ha sido condenado (eso pertenece al comiso de ganancias), sino de otras actividades delictivas llevadas a cabo por esa persona en el seno de dicha organización. Son numerosas las voces que vienen exigiendo la posibilidad de dar este contenido al comiso, puesto que consideran que es la única manera de luchar de forma eficaz contra la criminalidad organizada. Para proceder al comiso de un bien en la actualidad es necesario demostrar que éste proviene del delito concreto enjuiciado, no de otro distinto, lo que resulta de gran dificultad en el ámbito de la delincuencia organizada ${ }^{56}$.

55 Tanto el Consejo General del Poder Judicial como el Consejo Fiscal realizan esta interpretación del comiso ampliado en los informes citados supra.

Para evitar las dudas que a este respecto surgen de la lectura del segundo párrafo del 127.1 el Consejo Fiscal propone el siguiente cambio en su redacción: «El juez o tribunal podrá ampliar el decomiso a los efectos, bienes, instrumentos y ganancias relacionados o procedentes de cualquier actividad delictiva cometido en el marco de una organización criminal. A estos efectos se entenderá que proviene de actividad delictiva el patrimonio de todas y cada una de las personas condenadas por delitos cometidos en el seno de la organización criminal cuyo valor sea desproporcionado con respecto a los ingresos obtenidos legalmente por cada una de dichas personas».

56 Gracia Martín, L.: «Las consecuencias..., op. cit., p. 569, afirma que tal y como está la regulación actual, el comiso de ganancias solo es posible respecto a «ganancias ilícitas respecto de las que se pruebe de un modo pleno que traen causa precisamente del hecho delictivo concreto que sea objeto de enjuiciamiento en cada caso, y no de aquellos otros respecto de los que no pueda probarse su vinculación directa con el delito enjuiciado por mucho que exista una convicción acerca de su procedimiento ilicito». En el mismo sentido Choclán Montalvo, J.A : El patrimonio..., op. cit., pp. 50 y 51 , cree que es necesario que se pueda decomisar «cualquier bien tenido ilícitamente por el acusado, aunque no pueda probarse su vinculación con el concreto delito enjui- 
Es la primera vez que se reguló el comiso ampliado en el CP, pero no es la primera vez que se pretendió dar ese contenido al comiso. En relación con el tráfico de drogas, el Pleno de la Sala Penal del TS acordó el 5 de octubre de 1998 que «El comiso de las ganancias a que se refiere el artículo 374 del Código Penal debe extenderse a las ganancias procedentes de operaciones anteriores a la concreta operación descubierta y enjuiciada, siempre que se tenga por probada dicha procedencia y se respete en todo caso el principio acusatorio». Como puede verse, en relación con delitos de tráfico de drogas y sin exigir ninguna vinculación con organizaciones criminales, el TS ya está dando al comiso un contenido similar, si no igual, al del comiso ampliado. Desde que el Pleno del TS aprobó dar al comiso relacionado con delitos de tráfico de drogas el citado contenido hasta la actualidad, la jurisprudencia del $\mathrm{TS}^{57}$ se ha consolidado en este sentido.

\subsubsection{El problema de la presunción}

Decía el último inciso del párrafo segundo del art. 127.1 CP (reforma de 2010) que «se entenderá que proviene de la actividad delictiva el patrimonio de todas y cada una de las personas condenadas por delitos cometidos en el seno de la organización o grupo criminal o terrorista o por un delito de terrorismo cuyo valor sea desproporcionado con respecto a los ingresos obtenidos legalmente por cada una de dichas personas».

De la lectura de este inciso parece derivarse que si el juez o tribunal que ha condenado a una persona por cometer un delito en el marco de una organización criminal comprueba que el patrimonio de dicha persona es desproporcionado teniendo en cuenta cuáles son sus ingresos legales, automáticamente ese patrimonio puede ser objeto de decomiso porque se considera que proviene de actividades delictivas distintas a la que ha sido juzgada y cometidas también en el marco de dicha organización.

Si interpretamos de esta manera la versión de 2010 del art. 127.1 CP parece discutible su constitucionalidad, puesto que se vulnera la presunción de inocencia al establecerse una inversión de la carga de la prueba, es decir, es el condenado el que tiene que demostrar que ese patrimonio ha sido conseguido de manera lícita ${ }^{58}$.

ciado, pero sí con una habitual dedicación al delito». De esta opinión también Bacigalupo Sagesse, S.: Ganancias ilícitas..., op. cit., p. 90 y Aguado Correa, T.: El comiso..., op. cit., pp. 112 y ss.

${ }^{57}$ Entre otras las SSTS 19-9-2006, 20-9-2005, 24-6-2005, 14-7-2004, 30-5-2003 y 20-9-2002.

58 El CGPJ en el informe arriba citado, cuestiona la inconstitucionalidad de esta figura tal y como el legislador la regula en el PCP. 
Nos parece que la interpretación que hay que hacer de este artículo no era esta que, efectivamente, plantearía graves problemas de constitucionalidad, sino una bien distinta. No creemos que los jueces o tribunales puedan, de manera automática, imponer el comiso ampliado por el simple hecho de que exista una desproporción entre el patrimonio del condenado y sus ingresos legales. La DM 2005/212 en sus motivos se refiere a la necesidad de crear mecanismos para lograr una «mitigación de la carga de la prueba» (no habla de «invertir» la carga de la prueba), y los supuestos recogidos en el art. 3.2 de dicha DM se refieren a que el órgano jurisdiccional, antes de decretar el comiso ampliado «esté plenamente convencido» «basándose en hechos concretos» de que los bienes provienen de la actividad delictiva del sujeto.

En un sentido parecido, el Pleno del TS arriba citado contempla la posibilidad de decomisar ganancias procedentes de operaciones de tráfico de drogas anteriores a la enjuiciada «siempre que se tenga por probada dicha procedencia» y que haya suficientes datos que permitan conectar dicho patrimonio con otras operaciones de tráfico de droga ${ }^{59}$.

Ya desde entonces parecía adecuado que para aplicar el comiso ampliado, además de existir la mencionada desproporción, el juez o tribunal que la decrete tendría que haber justificado su decisión explicando los motivos que le llevan a concluir, tras un razonamiento lógico-deductivo, que dicha desproporción se debe a que el patrimonio del condenado proviene de actividades delictivas. Se trataría, por tanto, de utilizar la denominada prueba indiciaria, que no plantea problemas de constitucionalidad según reiterada jurisprudencia ${ }^{60}$.

${ }^{59}$ Durante la discusión anterior a la aprobación en el Pleno algunos Magistrados planteaban la necesidad de valorar conjuntamente cuatro indicios para conectar el patrimonio del condenado con otras operaciones de tráfico de drogas: «a) Intervención de una persona enjuiciada en una operación importante de tráfico de drogas, b) Ocupación de dinero en una cantidad desproporcionada a sus medios legales de vida, c) Anomalía en la tenencia de dicha cantidad de dinero por ser inusual en los usos modernos, como por ejemplo tener en metálico grandes cantidades en casa, d) Ausencia de explicación razonable de la procedencia lícita de dicho dinero»

${ }^{60}$ Esta parece ser también la postura que mantiene el Consejo fiscal en su informe cuando afirma que se trata de presunción que será «en todo caso objeto de valoración judicial». En el mismo sentido. Aguado Correa, T.: El comiso..., op. cit., pp. 112 y ss y las SSTS mencionadas en la nota $\mathrm{n}^{\circ} 38$, entre otras.

Choclán Montalvo afirma que «no cabe establecer en este campo inversiones de las reglas de la prueba, si con ello se pretende una posición extrema en el sentido de que en todo caso en que el sujeto no pueda ofrecer prueba sobre el origen del patrimonio se entiende que ésta tiene una procedencia ilícita», y considera que, "en realidad, cuando se proponen soluciones tendentes a la inversión de la carga de la prueba, probablemente no se pretenden estas consecuencias radicales, sino que se está haciendo referencia a una cuestión distinta, como es la de que el juez pueda llegar a la convicción sobre el 
Y, por supuesto, no hay ningún problema en admitir prueba en contrario, por lo que nos parece que con esta interpretación no se vulnera la presunción de inocencia ni se produce una inversión de la carga de la prueba.

Otro principio básico en nuestro ordenamiento jurídico-penal es el principio acusatorio que, sin dudas, también tendría que respetarse en relación con el comiso ampliado, es decir, tendría que haber una solicitud por parte de la acusación para que el juez o tribunal competente aplique esta figura ${ }^{61}$.

Algunas posturas quitan importancia a la posible vulneración de la presunción de inocencia y a la posibilidad de invertir la carga de la prueba puesto que en su opinión, la presunción que se establece en el art. 127.1 no se refiere a aspectos penales, sino que se trata de una presunción «en el ámbito de las consecuencias civiles del delito» ${ }^{62}$, «que no incide ni en el núcleo de la acción delictiva objeto de enjuiciamiento ni en la imputación de dicha acción a persona concreta y determinada; tal y como aparece configurada, opera respecto de personas condenadas en un proceso penal tramitado con todas las garantías y en las que el imputado ha podido ejercer debidamente su derecho a defenderse de las acusaciones formuladas contra él; sus consecuencias, por tanto, son exclusivamente de carácter patrimonial y económico, derivadas en todo caso de la acreditación de la comisión de actividades ilícitas relacionadas con el crimen organizado» ${ }^{63}$. En sentido contrario, el CGPJ ${ }^{64}$ afirma que la presunción pertenece al ámbito penal, puesto que lo que se presume es la previa comisión de un ilícito penal relacionado con los bienes a decomisar ${ }^{65}$.

origen ilícito de un patrimonio por medio del juicio de inferencia en que consiste la prueba de indicios». Choclán Montalvo, J.A : El patrimonio..., op. cit., pp. 33 y ss.

Si bien, Aguado Correa considera que en el ámbito de la delincuencia organizada el comiso de ganancias debería regirse por principios "parcialmente distintos, sobre todo en los que se refiere a la carga de la prueba sobre el origen de los bienes que posea una persona condenada por un delito relacionado con la delincuencia organizada». Y añade que «no estaría de más que para estos casos se previese una especie de inversión de la carga de la prueba de la certificación de origen, de manera, que correspondiese al autor acreditar la procedencia lícita de los bienes. En definitiva», concluye, «una facilitación de la prueba muy cercana a una inversión parcial de la carga de la prueba». Esta autora se refiere también a instrumentos supranacionales que parecen seguir esta línea. Aguado Correa, T.: «La regulación del comiso... «, op. cit. pp. 11 y ss.

${ }^{61}$ En este sentido Choclán Montalvo, J.A : El patrimonio..., op. cit., p. 32, así como la decisión del Pleno del TS antes citada y, entre otras, las siguientes SSTS 19-9-06, 192-2004, 20-9-2002, 6-3-2001, 11-2-1999.

62 Afirmación realizada por el Ministro de Justicia en el Congreso durante el debate de la enmienda da la totalidad. Véase nota 38.

${ }^{63}$ Informe del Consejo Fiscal.

${ }^{64}$ Informe del CGPJ.

${ }^{65}$ No estamos hablando en este punto de la naturaleza del comiso ampliado, sino del ámbito al que pertenece la presunción. Sobre la naturaleza del comiso recordemos que la 
Creemos que esta segunda postura es la adecuada puesto que lo que se presume es que, además de la infracción penal cometida en el marco de una organización o grupo criminal por la que el sujeto ha sido condenado, este ha llevado a cabo otras actividades delictivas en el seno de dicha organización que son las que han dado lugar al aumento de patrimonio no justificado. Por lo tanto, se está presumiendo la comisión de actividades delictivas, de infracciones penales, por lo que, a nuestro entender, la presunción sí pertenece al ámbito penal.

En relación con este punto hay otro aspecto ya señalado al tratar la DM 2005/212 que nos parece no quedó resuelto en la redacción del CP (reforma de 2010) y que pudo haber dado lugar a problemas prácticos. Hemos dicho que el comiso ampliado se decretará cuando el juez o tribunal llegue a la convicción de que el patrimonio del condenado proviene de la realización de actividades delictivas en el marco de una organización o grupo criminal. Entonces, ¿se dará inicio a un proceso penal para condenar esos hechos?, ¿y si han prescrito?, y si en un futuro juicio relativo a esos hechos se absuelve al acusado, ¿se le devolverá los bienes decomisados?

Por estas y otras cuestiones que hemos ido apuntando era necesaria una mayor reflexión por parte del legislador para poder dar con una técnica legislativa que supere las deficiencias apuntadas. En relación con la última de ellas, en la reforma penal de 2015, se procedió a introducir una mejora que soluciona parte de los problemas apuntados. En efecto, en la actualidad se señala que el comiso ampliado no será acordado cuando las actividades delictivas de las que provengan los bienes o efectos hubieran prescrito o hubieran sido ya objeto de un proceso penal resuelto por sentencia absolutoria o resolución de sobreseimiento con efectos de cosa juzgada. Todavía quedan patentes, como se puede ver, las dudas relacionadas con las demás preguntas que nos hemos planteado.

\section{Regulación especial}

La reforma penal de 2010 también introdujo ciertos cambios en algunas de las reglas especiales del comiso previstas en la Parte Especial del CP.

doctrina asumía mayoritariamente una naturaleza penal (véase nota 22). Podría pensarse que tal vez no se darían tantos escrúpulos en cuanto a una posible inversión de la carga de la prueba (con independencia de lo dicho en el texto sobre la naturaleza de la presunción) si admitiésemos que esta modalidad de comiso se trata de una medida civil o compensatoria, dirigida a impedir un enriquecimiento ilícito, tal como afirma un sector doctrinal respecto del comiso de ganancias (véase nota 23). No obstante, tanto nuestro TC como TS han mantenido la tesis de la naturaleza penal del comiso (entre otras, SSTC 159/85, 23/86, 21/87 y 92/1997 y STS de 27 de enero de 1997). Igualmente el propio TEDH ha declarado la naturaleza sancionatoria o punitiva del comiso (STEDH de 9 de febrero de 1995) y los propios instrumentos internacionales consideran el comiso como «sanción». 
Estas menciones permanecen en los mismos ámbitos delictivos hasta ahora vigentes, si bien las modificaciones más destacables se centran en el blanqueo de bienes y en el tráfico de drogas y, específicamente en estos ámbitos, en los supuestos de comisión de dichos delitos en el marco de una organización o grupo delictivo. Al igual que hemos visto que sucede con el art. 127 $\mathrm{CP}$, la reforma trató de adecuar la regulación a las provisiones de la DM 2005/212, principalmente en relación con el comiso ampliado, aunque pueda ser discutible, claro está, la mayor o menor fortuna con que dicha adecuación se ha llevado a cabo, como vamos a ver.

\subsection{Blanqueo de bienes}

\subsubsection{Art. 301.1, segundo apartado CP (reforma 2010)}

Este artículo fue modificado con la reforma penal del año 2010 (ni tampoco en la reforma de 2015), por lo que valen las consideraciones apuntadas en su momento al art. $301 \mathrm{CP}$ vigente.

\subsubsection{Art. 302.2 PCP}

La variación de este precepto no proviene del delito en sí, puesto que su apartado 1 mantiene la tipificación del blanqueo de bienes cuando se produzca en el marco de una organización dedicada a esta actividad delictiva. Lo que sí se modifica es el segundo apartado, al introducir expresamente la responsabilidad penal de la propia organización, en caso de cumplirse con las condiciones de imputación dispuestas en el art. 31 bis $^{66}$. Como ya hemos dicho, si hay condena conjunta a persona física y jurídica se acordará el comiso acompañando a la pena de ambos sujetos (o, en su caso, acorde al art. 127.4 CP en su versión de 2010).

No se explica por qué se ha suprimido la referencia a que los bienes objeto del delito son decomisables, tal como hacía el viejo art. 302.2 CP e incluso el art. 301.1, segundo apartado (que remite al art $374 \mathrm{CP}$ ). Esto nos llevaría a la paradoja de que tratándose de una agravación del art. 301

${ }^{66}$ Art. 302.2 CP (reforma de 2010): «2. En tales casos, cuando de acuerdo con lo establecido en el artículo 31 bis sea responsable una persona jurídica, se le impondrán las siguientes penas: a) Multa de dos a cinco años, si el delito cometido por la persona física tiene prevista una pena de prisión de más de cinco años. b) Multa de seis meses a dos años, en el resto de los casos. Atendidas las reglas establecidas en el artículo 66 bis, los jueces y tribunales podrán asimismo imponer las penas recogidas en las letras b) a g) del apartado 7 del artículo 33».

Vemos que para este delito también existe la posibilidad de que el juez aplique las medidas del art. 129, según la versión de 2010 del CP. 
resultaría más benévola en este aspecto. Creemos que lo adecuado, acorde a una interpretación sistemática y teleológica, sería entender que, al igual que el tipo base del art. $301 \mathrm{CP}$, debe extenderse la consideración de bienes decomisables al objeto del delito del tipo agravado.

Por remisión a la regulación genérica del art. 127 PCP vemos que el art. 302.2 CP reúne las condiciones para poder aplicar el comiso ampliado, con los problemas y consideraciones que hemos anunciado anteriormente. Nos remitimos, por tanto, a lo dicho anteriormente.

\subsection{Tráfico de drogas}

En materia de tráfico de drogas las modificaciones producidas vienen de la mano del art. 369, que se somete a algunas alteraciones (y que no fueron modificadas en la reforma penal de 2015). Además, se incluye un nuevo art. 369 bis, de especial importancia para la posibilidad de acordar el comiso ampliado. Por su parte, los arts. 371.2 y 374 CP no sufren ninguna variación de redacción, aunque algunos aspectos, por remisión a otros preceptos, deben ser reinterpretados.

\subsubsection{Art. 369.2 PCP}

Recordemos que el art. 369 regula un tipo agravado del tráfico de drogas cuando nos encontramos ante alguna de las circunstancias numeradas en el apartado ${ }^{167}$. De las tres mencionadas en su momento el CP elimina la segunda de ellas («el culpable perteneciere a una organización o asociación, incluso de carácter transitorio, que tuviese como finalidad difundir tales sustancias o

${ }^{67}$ Art. 369 CP (versión vigente): «1. Se impondrán las penas superiores en grado a las señaladas en el artículo anterior y multa del tanto al cuádruplo cuando concurran alguna de las siguientes circunstancias: $1 .{ }^{a}$ El culpable fuere autoridad, funcionario público, facultativo, trabajador social, docente o educador y obrase en el ejercicio de su cargo, profesión u oficio. $2{ }^{a}{ }^{a}$ El culpable participare en otras actividades organizadas o cuya ejecución se vea facilitada por la comisión del delito. $3{ }^{a}$ Los hechos fueren realizados en establecimientos abiertos al público por los responsables o empleados de los mismos. $4{ }^{a}$ Las sustancias a que se refiere el artículo anterior se faciliten a menores de 18 años, a disminuidos psíquicos o a personas sometidas a tratamiento de deshabituación o rehabilitación. $5{ }^{a}$ Fuere de notoria importancia la cantidad de las citadas sustancias objeto de las conductas a que se refiere el articulo anterior. $6 .{ }^{a}$ Las referidas sustancias se adulteren, manipulen o mezclen entre sí o con otras, incrementando el posible daño a la salud. 7. ${ }^{a}$ Las conductas descritas en el artículo anterior tengan lugar en centros docentes, en centros, establecimientos o unidades militares, en establecimientos penitenciarios o en centros de deshabituación o rehabilitación, o en sus proximidades. $8 .^{a}$ El culpable empleare violencia o exhibiere o hiciese uso de armas para cometer el hecho.». 
productos aun de modo ocasional»), que pasa a convertirse en un tipo autónomo en el art. 369 bis CP, como veremos. Las demás circunstancias (de particular interés la referida a la participación del culpable en otras actividades organizadas o cuya ejecución se vea facilitada por la comisión del delito y comisión de los hechos en establecimientos abiertos al público por los responsable o empleados de los mismo) se mantienen, en cuyo caso la referencia al comiso del art. 374 (conforme a la versión de 2015 del CP) siguen siendo respecto de la organización (o persona titular del establecimiento).

Aunque no se mencione expresamente el art. 31 bis CP, hemos de suponer que estamos ante un supuesto en el que se puede imputar el delito, junto a la persona física, también a la propia organización ${ }^{68}$, puesto que sólo entonces tendría sentido que se sometiese a confiscación el objeto del delito cuando este lo comete la entidad, de forma paralela a lo que el art. $374 \mathrm{CP}$ dispone en relación a las personas físicas.

\subsubsection{Art. 369 bis CP}

El legislador de 2010 introdujo en el CP un novedoso art. 369 bis en el que se tipifica la conducta de tráfico de drogas cuando esta se lleva a cabo en el marco de una organización delictiva dedicada a tal fin, con la agravación de las penas individuales que conlleva ${ }^{69}$. Merecen ser destacados dos aspectos de este nuevo tipo penal: primero, nos encontramos ante un supuesto más de

${ }^{68}$ Aunque tampoco queda del todo claro porque también podía ser que se refiriera al sistema de consecuencias accesorias del art. 129 PCP que, como dijimos, pervive junto al art. 31 bis PCP. Pero de ser así, entonces sería más difícil justificar coherentemente la referencia al comiso para la organización.

69 Art. 369 bis CP (que no ha sido modificada en las reformas posteriores a 2010, por llo que a la fecha se encuentra vigente): «Cuando los hechos descritos en el artículo 368 se hayan realizado por quienes pertenecieren a una organización delictiva, se impondrán las penas de prisión de nueve a doce años y multa del tanto al cuádruplo del valor de la droga si se tratara de sustancias y productos que causen grave daño a la salud y de prisión de cuatro años y seis meses a diez años y la misma multa en los demás casos.

A los jefes, encargados o administradores de la organización se les impondrán las penas superiores en grado a las señaladas en el párrafo primero.

Cuando de acuerdo con lo establecido en el artículo 31 bis una persona jurídica sea responsable de los delitos recogidos en los dos artículos anteriores, se le impondrán las siguientes penas:

a) Multa de dos a cinco años, o del triple al quíntuple del valor de la droga cuando la cantidad resultante fuese más elevada, si el delito cometido por la persona física tiene prevista una pena de prisión de más de cinco años.

b) Multa de uno a tres años, o del doble al cuádruple del valor de la droga cuando la cantidad resultante fuese más elevada, si el delito cometido por la persona física tiene prevista una pena de prisión de más de dos años no incluida en el anterior inciso. 
imputación jurídico-penal a la organización, pero sólo si esta ostenta personalidad jurídica, con lo que ello implica de cara a la posibilidad de acordar el comiso directamente contra ella. Y, segundo, derivado de lo anterior, el art. 369 bis nos vuelve a especificar que el comiso que acompañe a la pena de la entidad también incluirá a los bienes objeto del delito y a los productos y beneficios obtenidos directa o indirectamente por el delito.

\subsubsection{Art. 371.2 PCP}

El legislador de 2010 no plantea ninguna modificación al texto del art. $371 \mathrm{CP}$. A pesar de todo, habrá que tener en cuenta la remisión que hace este artículo al art. 369.2, precepto que sí se ha visto modificado, con las repercusiones ya comentadas respecto de la persona jurídica, por un lado, y del comiso ampliado, por otro.

\subsubsection{Art. 374 PCP}

Las reglas específicas del art. $374 \mathrm{CP}$ en materia de tráfico de drogas no sufren reforma, con lo que se mantienen las luces y sombras de dicha regulación. No obstante, a la vista de la inclusión del art. 31 bis CP habrá que entender que estas reglas especiales también son de aplicación a la persona jurídica, en caso de ser condenada penalmente, puesto que el apartado 1 de este artículo extiende su aplicación a los arts. 368 a 372 y tanto el delito recogido en el art. 369.2 como en el art. 369 bis es imputable a la persona jurídica, como hemos visto.

\subsection{Seguridad vial}

En este ámbito delictivo tampoco se han introducido variaciones de fondo en aquello que pudiera afectar al comiso. No obstante, cabe señalar que, en el marco de los delitos contra la seguridad vial, se reordena y corrige la técnica legislativa utilizada en el suprimido art. 381.3, que pasa a estar ubicado en el nuevo art. 385 bis ( El vehículo a motor o ciclomotor utilizado en los hechos previstos en este Capitulo se considerará instrumento del delito a los efectos de los artículos 127 y 128»). Con ello quedaron zanjadas las dudas respecto de las posibilidades de aplicación del comiso a todas las figuras previstas en el capítulo o, por el contrario, solo a las modalidades de conducción temeraria previstas en el art. 381 .

Atendidas las reglas establecidas en el artículo 66 bis, los jueces y tribunales podrán asimismo imponer las penas recogidas en las letras b) a g) del apartado 7 del artículo $33 »$. 


\title{
LA DECISIÓN MARCO 2005/212: ANTECEDENTE Y ORIGEN DE LAS ÚLTIMAS REFORMAS DEL COMISO COMO CONSECUENCIA ACCESORIA DEL DELITO
}

\author{
The framework decision 2005/212: background \\ and origin of the last reform of the confiscation \\ as a consequence of crime accessory
}

Itziar Casanueva Sanz

Itziar.casanueva@deusto.es

Soledad Gil Nobajas

sgil@deusto.es

\author{
Emilio José Armaza Armaza \\ Emilio.armaza@deusto.es \\ Universidad de Deusto (España)
}

http://dx.doi.org/10.18543/ed-66(2)-2018pp397-434

\section{Copyright}

Estudios de Deusto es una revista de acceso abierto, lo que significa que es de libre acceso en su integridad. Se permite su lectura, la búsqueda, descarga, distribución y reutilización legal en cualquier tipo de soporte sólo para fines no comerciales, sin la previa autorización del editor o el autor, siempre que la obra original sea debidamente citada y cualquier cambio en el original esté claramente indicado 